\title{
Residual Circulation in the Stratosphere and Lower Mesosphere as Diagnosed from Microwave Limb Sounder Data
}

\author{
JANUSZ ELUSZKIEWICZ* \\ Division of Geological and Planetary Sciences, California Institute of Technology, Pasadena, California
}

\author{
David Crisp, Richard Zurek, Lee Elson, Evan Fishbein, Lucien Froidevaux, and Joe Waters
}

Earth and Space Sciences Division, Jet Propulsion Laboratory, Pasadena, California

R. G. GRAINGER AND Alyn LAMBERT

Atmospheric, Oceanic, and Planetary Physics, University of Oxford, Oxford, United Kingdom

ROBERT HARWOOD

Department of Meteorology, Edinburgh University, Edinburgh, United Kingdom

GORDON PECKHAM

Department of Physics, Heriot-Watt University, Edinburgh, United Kingdom

(Manuscript received 21 March 1994, in final form 9 June 1995)

\begin{abstract}
Results for the residual circulation in the stratosphere and lower mesosphere between September 1991 and August 1994 are reported. This circulation is diagnosed by applying an accurate radiative transfer code to temperature, ozone, and water vapor measurements acquired by the Microwave Limb Sounder (MLS) onboard the Upper Atmosphere Research Satellite (UARS), augmented by climatological distributions of methane, nitrous oxide, nitrogen dioxide, surface albedo, and cloud cover. The sensitivity of the computed heating rates to the presence of Mt. Pinatubo aerosols is explored by utilizing aerosol properties derived from the measurements obtained by the Improved Stratospheric and Mesospheric Sounder instrument, also onboard UARS. The computed vertical velocities exhibit a semiannual oscillation (SAO) around the tropical stratopause, with the region of downward velocities reaching maximum spatial extent in February and August. This behavior reflects the semiannual oscillation in temperature and ozone and mimics that seen in past studies of the October 1978-May 1979 period based on data from the Limb Infrared Monitor of the Stratosphere onboard the Nimbus 7 satellite. The SAO vertical velocities are stronger during the northern winter phase, as expected if planetary waves from the winter hemisphere are involved in driving the SAO. A possible quasi-biennial oscillation (QBO) signal extending from the middle into the upper stratosphere is also hinted at, with the equatorial vertical velocities in the region 10-1 hPa significantly smaller (or even negative) in 1993/94 than in 1992/93. Despite the short data record, the authors believe that this pattem reflects a $Q B O$ signal rather than a coincidental interannual variability, since the time-height section of vertical velocity at the equator resembles that of the zonal wind. Wintertime highlatitude descent rates are usually greater in the Northem Hemisphere, but they also exhibit significant variability there. In the three northern winters analyzed in this study, strong downward velocities are diagnosed in the lower stratosphere during stratospheric warmings and are associated with enhanced wave forcing (computed as the momentum residual) in the mid- and upper stratosphere. The implications of the computed circulation for the distribution of tracers are illustrated by the example of the "double-peaked" structure in the water vapor distribution measured by MLS.
\end{abstract}

\section{Introduction}

The studies of the diabatic circulation in the middle atmosphere were pioneered by Murgatroyd and Singleton (1961), who used the diabatic heating rates com-

\footnotetext{
* Current affiliation: Center for Meteorology and Physical Oceanography, Massachusetts Institute of Technology, Cambridge, Massachusetts.
}

puted by Murgatroyd and Goody (1958). The latter only considered radiative transfer by carbon dioxide and ozone, with the distribution of the latter based on

Corresponding author address: Dr. Janusz Eluszkiewicz, Center for Meteorology and Physical Oceanography, Massachusetts Institute of Technology, Bldg. 54-1719, Cambridge, MA 02139. E-mail: jel@quovadis.mit.edu 
the sparse information available at the time. Even so, the resulting diabatic circulation captured most of the essential features of the "Brewer-Dobson" circulation deduced from early observations of the meridional distribution of water vapor and ozone.

More recent derivations of the zonally symmetric transport in the stratosphere have been based on the transformed Eulerian-mean (TEM), or residual-mean, system of equations, in which the observed temperature field is used to compute time tendency and horizontál heat flux terms, in addition to the infrared cooling needed to determine the net diabatic heating. The advent of nearly global temperature fields retrieved from satellite-borne remote sensors has provided the critical input to these calculations. Of particular note are the diagnostic calculations based on climatologies derived from several satellites (Rosenfield et al. 1987; Callis et al. 1987; Shine 1989; Choi and Holton 1991) and those based on the observations by the Nimbus 7 Limb Infrared Monitor of the Stratosphere (LIMS) over the period October 1978-May 1979 (Solomon et al. 1986; Hitchman and Leovy 1986; Gille et al. 1987; Callis et al. 1987; Pawson and Harwood 1989). The main advantage of the LIMS-based studies was the high vertical resolution of the temperature and constituent data retrieved from LIMS, while the climatological studies had the benefit of investigating the circulation over a full seasonal cycle. The vertical resolution and spatial coverage obtained by LIMS were especially useful in the study of large-scale phenomena like atmospheric tides and the semiannual oscillation (SAO), although only one cycle of the latter was covered during the operational period of LIMS.

The launch of the Upper Atmosphere Research Satellite (UARS) on 12 September 1991 (Reber et al. 1993 ) has provided a new dataset with the vertical resolution of temperature and constituent measurements comparable to LIMS, but which now extends for several instruments into the fifth year of nearly continuous observations. In this paper we use the UARS Microwave Limb Sounder (MLS) (Waters et al. 1993) data records to compute the residual circulation in the stratosphere, with emphasis on the middle stratosphere and stratopause region. Our purpose is to use a detailed radiative transfer code to see the potential impact on the derived residual circulation there of semiannual and even quasi-biennial oscillations that are apparent in the multiyear MLS records of retrieved temperature, ozone, and water vapor fields (Ray and Holton 1994; Froidevaux et al. 1994; Mote et al. 1995). While this is done in the context of deriving the full stratospheric residual circulation, results for the lower stratosphere show some sensitivity to the specification of tropospheric cloud cover and surface albedo, to the presence and specification of volcanic aerosols, and even to the form of boundary conditions imposed for the numerical solution of the residual streamfunction equation. However, these effects (to be discussed in a future paper) do not affect the temporal variation of the circulation derived at higher altitudes. Thus, we will focus here on investigating the character and interannual variation of the SAO using the unprecedented three-year limb-sounding stratospheric dataset provided by the UARS MLS.

The formalism used is presented in section 2 . The input fields for the diabatic heating calculation are described in section 3 , where we also discuss how we deal with one unique aspect of the UARS MLS data, namely the shifting pattern of high-latitude coverage caused by the $57^{\circ}$ inclination of the satellite orbit. A description of a sophisticated radiative transfer code is given in section 4 . The resulting residual circulation is discussed in section 5 . The semiannual oscillation and its implications for stratospheric transport are discussed in section 6 . The paper concludes with a summary in section 7 .

\section{Theoretical framework}

The residual circulation $\left(\bar{v}^{*}, \bar{w}^{*}\right)$ is of primary importance in two-dimensional stratospheric modeling (see, e.g., WMO 1986). It is governed by the TEM equations

$$
\begin{gathered}
\frac{\partial \bar{u}}{\partial t}-\left[f-\frac{1}{a \cos \phi} \frac{\partial}{\partial \phi}(\bar{u} \cos \phi)\right] \bar{v}^{*} \\
+\bar{w}^{*} \frac{\partial \bar{u}}{\partial z}=\bar{X}+\frac{1}{\rho a \cos \phi} \nabla^{\mathscr{F}} \\
\frac{\bar{u}^{2} \tan \phi}{a}+f \bar{u}+\frac{1}{a} \frac{\partial \bar{\Phi}}{\partial \phi}=g \approx 0 \\
\frac{\partial \bar{\Phi}}{\partial z}-\frac{R \bar{\theta}}{H} e^{-\kappa z / H}=0 \\
\frac{1}{a \cos \phi} \frac{\partial}{\partial \phi}\left(\bar{v}^{*} \cos \phi\right)+\frac{1}{\rho} \frac{\partial}{\partial z}\left(\rho \bar{w}^{*}\right)=0 \\
\frac{\partial \bar{\theta}}{\partial t}+\frac{\bar{v}^{*}}{a} \frac{\partial \bar{\theta}}{\partial \phi}+\bar{w}^{*} \frac{\partial \bar{\theta}}{\partial z}=\bar{Q}-\frac{1}{\rho} \frac{\partial}{\partial z} \\
\times\left[\rho\left(\overline{v^{\prime} \theta^{\prime}} \frac{1}{a} \frac{\partial \bar{\theta} / \partial \phi}{\partial \bar{\theta} / \partial z}+\overline{w^{\prime} \theta^{\prime}}\right)\right]
\end{gathered}
$$

The notation is standard (Andrews et al. 1987). The vector $\mathscr{F}$ appearing on the right-hand side of Eq. (1) is called the Eliassen-Palm (E-P) flux and its divergence represents the contribution to the zonal momentum from planetary waves, whereas the term $\bar{X}$ denotes the contribution from small-scale waves and other subgrid processes. In Eq. (2), the term $\&$ denotes the contribution to the meridional momentum from waves and unresolved processes and is usually neglected. The second term (with the minus sign) on the right-hand side of Eq. (5) will be referred to as eddy heating and denoted by $\bar{E} e^{\kappa z / H}$. The first term $\bar{Q}$ is the net diabatic heating, equal to $\left(\bar{J} / c_{p}\right) e^{\kappa z / H}$, where $J$ is the diabatic 
heating rate per unit mass. In the following, $\bar{J} / c_{p}$ will be referred to as the "net diabatic heating" and expressed in units of kelvins per day. In the middle atmosphere, this heating is the balance between absorption of solar radiation and emission and absorption of infrared radiation. The availability of an accurate radiative transfer model, in addition to the distributions of temperature and of the radiatively active gases, is essential for computing the net radiative heating rates, since the latter are obtained by subtracting the almostequal solar heating and thermal cooling rates at each stratospheric level. Thus, small errors in either of these components can produce much larger errors in the net heating rates and in the strength of the derived residual circulation. This is particularly true at levels in the middle and lower stratosphere, where the solar heating and thermal cooling rates often differ by less than $20 \%$. Crisp $(1986,1989,1990)$ has developed a variety of accurate methods for finding radiative fluxes and heating rates in scattering and absorbing planetary atmospheres. We have combined these methods to produce a comprehensive radiative transfer model that can accommodate, with one exception, the radiative processes known to be important in the stratosphere and lower mesosphere, including absorption, emission, and multiple scattering by gases, clouds, and aerosols. Our model is particularly well suited for studying the semiannual oscillation in the stratopause region, since it uses an accurate representation of the Voigt line shape (Humliček 1982; Crisp 1990) and of the line strength distribution (Crisp et al. 1986). The application of this model to the present dataset is described in section 4 .

The residual circulation $\left(\bar{v}^{*}, \bar{w}^{*}\right)$ can be calculated from Eqs. (4) and (5), provided the distributions of temperature and $\bar{Q}$ are known, and the eddy heating term on the right-hand side of Eq. (5) is neglected or estimated. This term, which represents cross-isentropic heat transport by eddies, is expected to be generally small in the middle atmosphere (Hitchman and Leovy 1986; Andrews et al. 1987; Gille et al. 1987; C. Marks as quoted by Shine 1989), but can be significant during disturbed conditions (Eluszkiewicz et al. 1995). The findings of our investigation into its magnitude are discussed in section 5 . When the eddy heating and temperature tendency terms in Eq. (5) are neglected, the residual velocity components computed from Eqs. (4) and (5) are referred to as the diabatic circulation (Gille et al. 1987). In this study, the temperature tendency term will be retained and the eddy heating term estimated and then neglected.

\section{Input data}

\section{a. Global fields from MLS data}

In the present study, the fields of temperature, ozone, and water vapor measured by the MLS instrument will be used in the radiative transfer calculations. These fields are taken from the latest files (version 3) available at the Central Data Handling Facility at the Goddard Space Flight Center. The methodology of retrieving atmospheric fields from MLS observations is described by Froidevaux et al. (1994b). The vertical resolution of MLS measurements is on the order of 5 $\mathrm{km}$ or better (see Table 1 for a list of UARS pressure levels at which geophysical quantities are retrieved from MLS measurements). In this investigation, the zonally and time-averaged fields will be used for the most part. These averages are obtained as the $\Psi$ ( $m$ $=0, \sigma_{n}=0$ ) component in the Fourier expansion

$$
\psi(\lambda, t)=\sum_{m=0}^{M} \sum_{n=0}^{N} \Psi\left(m, \sigma_{n}\right) \exp \left[i\left(m \lambda+\sigma_{n} t\right)\right],
$$

where the field $\psi(\lambda, t, \phi, z)$ is defined over longitude $\lambda$, time $t$, latitude $\phi$, and $\log$ pressure $z, m$ is the longitudinal wavenumber, and $\sigma_{n}$ is the frequency. The Fourier components $\Psi\left(m, \sigma_{n}\right)$ (which are functions of latitude and log pressure) are computed from the individual profile data by means of an asynoptic mapping technique described by Elson and Froidevaux (1993). This technique, based on the work by Salby (1982) and Lait and Stanford (1988), accounts for the asynchronous nature of the MLS data-that is, the systematic sampling of different longitudes at different times.

The $57^{\circ}$ inclination of the UARS orbit also restricts the latitudinal coverage of the MLS. Since the MLS instrument views the atmospheric limb in a direction perpendicular to the orbit track, the latitudinal coverage at any time extends to about $80^{\circ}$ in one hemisphere, but to only $34^{\circ}$ in the other hemisphere. Approximately once a month, the spacecraft is rotated in a yaw maneuver by $180^{\circ}$ in its track, at which point the latitudinal

TABLE 1. Retrieval levels for UARS fields used in the diabatic heating calculations. Note: MLS values at odd UARS levels within the range of measurements are obtained by linear interpolation between adjacent even levels.

\begin{tabular}{rccccc}
\hline \hline $\begin{array}{c}\text { UARS } \\
\text { level }\end{array}$ & $\begin{array}{c}\text { Pressure } \\
{[\mathrm{hPa}]}\end{array}$ & $\begin{array}{c}\text { MLS } \\
\text { temperature }\end{array}$ & $\begin{array}{c}\text { MLS } \\
\text { ozone }\end{array}$ & $\begin{array}{c}\text { MLS water } \\
\text { vapor }\end{array}$ & $\begin{array}{c}\text { ISAMS } \\
\text { aerosol }\end{array}$ \\
\hline 22 & 0.22 & & & $\times$ & \\
21 & 0.31 & & & & \\
20 & 0.46 & $\times$ & $\times$ & $\times$ & \\
19 & 0.68 & & & & \\
18 & 1.0 & $\times$ & $\times$ & $\times$ & \\
17 & 1.4 & & & & \\
16 & 2.2 & $\times$ & $\times$ & $\times$ & \\
15 & 3.1 & & & & \\
14 & 4.6 & $\times$ & $\times$ & $\times$ & $\times$ \\
13 & 6.8 & & & & $\times$ \\
12 & 10 & $\times$ & $\times$ & $\times$ & $\times$ \\
11 & 14 & & & & $\times$ \\
10 & 22 & $\times$ & $\times$ & $\times$ & $\times$ \\
9 & 31 & & & & $\times$ \\
8 & 46 & & $\times$ & $\times$ & $\times$ \\
7 & 68 & & & & $\times$ \\
6 & 100 & & $\times$ & & \\
\hline
\end{tabular}


coverage is reversed between the two hemispheres. The period between two consecutive yaw maneuvers is referred to as one UARS month, with 10 UARS months in a year. To obtain the global fields necessary for a proper introduction of the boundary conditions on the residual circulation, quasi-biweekly averages corresponding to periods before and after the yaw times are selected for the calculations (biweekly, rather than monthly, averages were chosen to better approximate simultaneity of the north- and south-viewing measurements). These averages are formed as follows. First, the fields of $\Psi\left(m=0, \sigma_{n}=0\right)$ (with $\Psi=T,\left[\mathrm{O}_{3}\right]$, and $\left.\left[\mathrm{H}_{2} \mathrm{O}\right]\right)$ are computed for a 7.2-day period (108 orbits) preceeding a yaw maneuver, giving the zonally averaged distributions of temperature, ozone, and water vapor between $30^{\circ}$ in one hemisphere and $90^{\circ}$ in the other hemisphere (the values poleward of $80^{\circ}$ are obtained by linear extrapolation in latitude). Using these distributions, the field of $\bar{J} / c_{p}$ is computed. Then the corresponding field is computed for a 7.2-day period after the yaw and the results are averaged between $30^{\circ} \mathrm{S}$ and $30^{\circ} \mathrm{N}$, where the south- and north-viewing fields overlap. Poleward of $30^{\circ}$ the fields of $\bar{J} / c_{p}$ prior to or after the yaw are used, as appropriate. The yaw dates considered in this study and their averaging periods are listed in Table 2. For the north-viewing periods after April 1994, when MLS was operational every other day, the averaging period is 9 days (with the data on nonoperational days filled in by linear interpolation in time). On the other hand, when the averaging periods were occasionally shorter than 7.2 days due to spacecraft or instrumental problems, the zonally averaged fields are constructed by simple averaging of individual profile (Level $3 \mathrm{AL}$ ) data. It should be noted that the effects of using the $\Psi\left(m=0, \sigma_{n}=0\right)$ components rather than the zonally averaged Level $3 \mathrm{AL}$ data are small; for example, the zonally averaged solar heating and thermal cooling change by less than $0.05 \mathrm{~K}^{2}$ day $^{-1}$ depending on this choice, except at extreme latitudes, when the effect can slightly exceed $0.1 \mathrm{~K} \mathrm{day}^{-1}$. However, mapped fields constructed from Fourier coefficients are better suited for three-dimensional heating calculations, such as those mentioned in section 5 .

\section{b. Temperature}

Based on validation studies (Fishbein et al. 1994), it is presently believed that MLS temperature retrievals are reliable in the pressure range $22-0.46 \mathrm{hPa}$ ( see Table 1). At pressures greater than $22 \mathrm{hPa}$, temperatures provided by the National Meteorological Center (NMC) are utilized, since the $\mathrm{O}_{2}$ line used for pressure and temperature retrievals becomes saturated. At pressures lower than $0.46 \mathrm{hPa}, \mathrm{MLS}$-retrieved temperature

TABLE 2. Averaging periods for radiative heating and residual circulation calculations. South-viewing period is given first.

\begin{tabular}{|c|c|c|}
\hline Yaw & Label & Averaging periods \\
\hline 1 & S-0 91 & 21-25 September and 1-8 October 1991 \\
\hline 2 & $\mathrm{O}-\mathrm{N} 91$ & 6-13 November and $19-26$ October 1991 \\
\hline 3 & $\mathbf{N}-\mathbf{D} 91$ & 26 November - 3 December and 5-12 December 1991 \\
\hline 4 & $\operatorname{Jan} 92$ & 15-22 January and 6-13 January 1992 \\
\hline 5 & Feb 92 & 6-13 February and 15-22 February 1992 \\
\hline 6 & Mar 92 & 24-31 March and 15-22 March 1992 \\
\hline 7 & A-M 92 & 23-30 April and 2-9 May 1992 \\
\hline 8 & M-J 92 & 15-22 June and 24-31 May 1992 \\
\hline 9 & Jul 92 & $5-12$ July and $18-25$ July 1992 \\
\hline 10 & Aug 92 & 14-21 August and 5-12 August 1992 \\
\hline 11 & Sep 92 & 13-20 September and 22-29 September 1992 \\
\hline 12 & $\mathrm{O}-\mathrm{N} 92$ & 30 October-6 November and $21-28$ October 1992 \\
\hline 13 & $\mathrm{~N}-\mathrm{D} 92$ & 21-28 November and 30 November-6 December 1992 \\
\hline 14 & $\operatorname{Jan} 93$ & 10-17 January and 1-8 January 1993 \\
\hline 15 & Feb 93 & 1-8 February and 10-17 February 1993 \\
\hline 16 & Mar 93 & 20-27 March and 11-18 March 1993 \\
\hline 17 & A-M 93 & 21-25 April and 27 April-4 May 1993 \\
\hline 18 & $\mathrm{M}-\mathrm{J} 93$ & 29 May-5 June and 20-27 May 1993 \\
\hline 19 & J-J 93 & 30 June-7 July and 9-16 July 1993 \\
\hline 20 & J-A 93 & 9-16 August and 25 July-1 August 1993 \\
\hline 21 & Sep 93 & 9-16 September and 23-30 September 1993 \\
\hline 22 & $\mathrm{O}-\mathrm{N} 93$ & 25 October-1 November and 22-23 October 1993 \\
\hline 23 & N-D 93 & 17-24 November and 26 November -3 December 1993 \\
\hline 24 & D-J $93 / 94$ & 6-13 January and 28 December -4 January $1993 / 94$ \\
\hline 25 & J-F 94 & 25 January and 5-12 February 1994 \\
\hline 26 & Mar 94 & 18-19 March and 8-15 March 1994 \\
\hline 27 & $\mathrm{~A}-\mathrm{M} 94$ & 14-21 April and 23 April-1 May 1994 \\
\hline 28 & May 94 & 24-31 May and 13-21 May 1994 \\
\hline 29 & J-J 94 & 26 June -3 July and 6-14 July 1994 \\
\hline 30 & J-A 94 & 5-12 August and 26 July-3 August 1994 \\
\hline
\end{tabular}


gradients are too steep (compared with climatology), due to decreasing sensitivity, leading to a persistent cold bias at $0.22 \mathrm{hPa}$. Because of the nature of radiative transfer, this bias affects the cooling rates at greater pressures. The MLS team is currently working on a scheme for improving temperature estimates near the stratopause.

\section{c. Ozone}

The MLS instrument measures ozone concentrations at pressures $0.46 \leqslant p \leqslant 100 \mathrm{hPa}$ using emission at 183 and $205 \mathrm{GHz}$ (Froidevaux et al. 1994a,b). In this paper, values from the $205-\mathrm{GHz}$ band will be used. The sensitivity of the computed solar heating rates to replacing these values with the $183-\mathrm{GHz}$ measurements was found to be smaller than $5 \%$, which is less than the estimated accuracy of our solar-heating code. At pressures lower than $0.46 \mathrm{hPa}$, values from the UARS prelaunch climatology are used. Between 100 and 464 $\mathrm{hPa}$, ozone abundances at the UARS pressure levels are constrained to values obtained from the two-dimensional model of Lawrence Livermore National Laboratory. At lower altitudes, ozone concentrations have been set to the assumed $464-\mathrm{hPa}$ value. A test calculation for January 1992, in which ozone abundances at pressures greater than $464 \mathrm{hPa}$ were set to zero, produced relative changes of less than $5 \%$ in the computed diabatic velocities, except in some regions of near-zero velocities, particularly in the lower stratosphere. At latitudes where the $205-\mathrm{GHz}$ ozone abundances at 100 $\mathrm{hPa}$ occasionally become negative due to poor signalto-noise ratio (Froidevaux et al. 1994b), these abundances were set to zero.

\section{d. Water vapor and other constituents}

Water vapor concentrations are measured in the 183$\mathrm{GHz}$ band (Lahoz et al. 1994). For the period between 2 June and 17 July 1992 , when the $\mathrm{H}_{2} \mathrm{O}$ channel was not operational, climatological values compiled by the UARS Science Team are used. The UARS prelaunch water vapor climatology in the stratosphere is based primarily on the LIMS data (e.g., Russell et al. 1984), assuming some seasonal symmetry to extend this database to the northern summer and fall periods not observed by LIMS. The MLS $\mathrm{H}_{2} \mathrm{O}$ retrievals are currently considered most reliable in the 46 to $0.2 \mathrm{hPa}$ pressure range; the values at $100 \mathrm{hPa}$ are mostly climatology, as are the values in the troposphere and at $46 \mathrm{hPa}$ at high latitudes. After 25 April 1993, when the $183-\mathrm{GHz}$ radiometer ceased to operate, the fields for the appropriate season from the period April 1992-March 1993 (yaws 7-16 in Table 2) are used.

The MLS fields are augmented by distributions of methane and nitrous oxide from the prelaunch climatology and by the LIMS daytime distribution of $\mathrm{NO}_{2}$ extended to a full seasonal cycle on the assumption of hemispheric symmetry for the respective season. The tropospheric $\mathrm{CO}_{2}$ mixing ratio is computed by means of the expressions given by Keeling et al. (1989) and a stratospheric $\mathrm{CO}_{2}$ concentration of $346 \mathrm{ppmv}$ is assumed.

\section{e. Stratospheric aerosols}

Following the eruption of Mt. Pinatubo in June 1991, there was a period of significantly enhanced aerosol concentrations in the stratosphere. We have not yet included Pinatubo aerosols in our routine calculations, but have explored the sensitivity of the computed heating rates to the presence of aerosols for a few selected profiles spanning a range of times and locations. These profiles have been obtained from measurements taken by another UARS instrument, the Improved Stratospheric and Mesospheric Sounder (ISAMS). ISAMS aerosol measurements are made at $\mathbf{1 2 . 1} \mu \mathrm{m}$ (Lambert et al. 1995) and have been extrapolated to cover the wavelength range 0.1 to $25 \mu \mathrm{m}$ using the method described in Grainger et al. (1995a). This procedure uses Mie calculations based on modified refractive indices for $\mathrm{H}_{2} \mathrm{SO}_{4}$ (Grainger et al. 1995b) and takes into account changes in the composition and effective radius of the aerosol drops. The wavelength-dependent extinction and scattering coefficients and the asymmetry parameter are estimated at nine UARS vertical levels equally spaced in $\log$ pressure between 100 and $4 \mathrm{hPa}$ ( see Table 1). We discuss the results of including aerosols into the heating calculations in section $4 \mathrm{~b}$.

\section{Diabatic heating}

The heating calculations are performed on a grid that has 61 vertical levels equally spaced in log pressure between the ground and $0.01 \mathrm{hPa}$. This resolution, which was chosen after extensive testing (Gerstell 1995), is twice the vertical resolution of the standard UARS pressure grid and four times the resolution of MLS retrievals. The values of the input fields at nonMLS levels are obtained by linear interpolation in log pressure. The meridional spacing in the calculations is $5^{\circ}$. In applications where three-dimensional input fields are required, the longitudinal spacing is also $5^{\circ}$.

\section{a. Solar heating}

The absorption of sunlight by $\mathrm{O}_{3}$ at $\mathrm{UV}$ and visible wavelengths provides the majority of the solar heating at most stratospheric levels, but absorption within nearinfrared $\mathrm{H}_{2} \mathrm{O}, \mathrm{CO}_{2}$, and $\mathrm{O}_{2}$ bands also produces substantial heating $(10 \%$ to $30 \%)$ in the lower stratosphere. A variety of other gases $\left(\mathrm{N}_{2} \mathrm{O}, \mathrm{CH}_{4}, \mathrm{NO}_{2}\right)$ contribute much less solar heating, but are included here for completeness, as is Rayleigh scattering and scattering by tropospheric clouds. Rayleigh scattering indirectly increases solar heating at some levels by increasing the pathlengths traveled by solar photons, and de- 


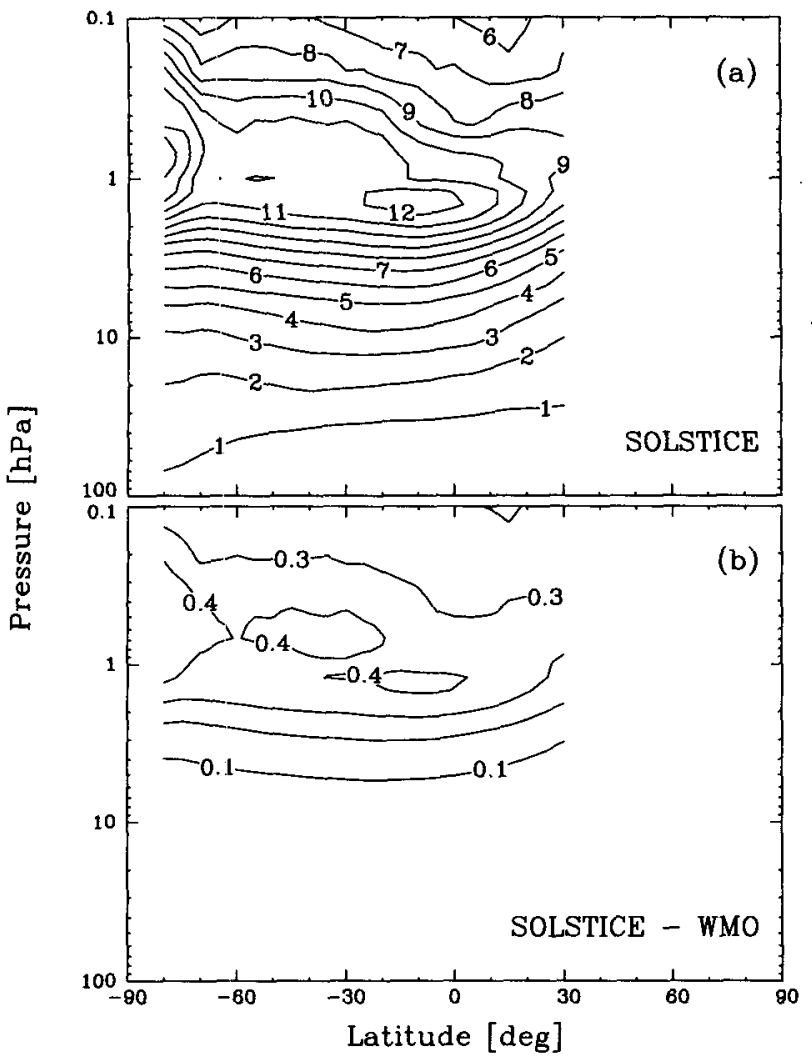

FIG. 1. (a) Solar heating rates for the period 1-8 February 1993. The solar fluxes at the top of the atmosphere are from the SOLSTICE instrument onboard UARS (Rottman et al. 1993). (b) Difference between the heating rates shown in panel (a) and heating rates computed using solar fluxes from WMO (1986).

creases it at other levels by reflecting solar radiation back to space before it can be absorbed by the atmosphere or the surface. Tropospheric clouds also produce small increases in the stratospheric heating rates by reflecting sunlight back through the stratosphere for a second pass, again increasing the photon pathlength and the probability of absorption.

To account for the scattering and absorption of sunlight by these processes, solar fluxes and heating rates are obtained from a multiple scattering model based on the multilevel $\delta$-Eddington/adding method (Crisp 1986). This approach should be accurate in moderately wide spectral intervals at ultraviolet and visible wavelengths where the extinction of sunlight is dominated by Rayleigh scattering and continuum absorption. On the other hand, it is not strictly valid within broad spectral regions occupied by the strong near-infrared $\mathrm{H}_{2} \mathrm{O}$, $\mathrm{CO}_{2}$, and $\mathrm{O}_{2}$ vibration-rotation bands, since the gas absorption coefficients vary rapidly with wavelength in these intervals, and the broadband absorption does not satisfy the Bougher-Lambert-Beer Law (Liou 1980; Goody and Yung 1989), as the multiple scattering model required. However, the heating rate errors as- sociated with the violation of Beer's law rarely exceed 5\% compared with rigorous line-by-line calculations, and for cloudy or aerosol-laden atmospheres the present method is more accurate than an alternative twostream nonscattering model (Gerstell et al. 1995). The broadband gas absorption at near-IR wavelengths is evaluated by means of a Voigt quasi-random model (Crisp 1990; Santee and Crisp 1993). The solar spectrum is divided into 755 spectral intervals, equally spaced in wavenumber between 0.125 and $5.26 \mu \mathrm{m}$, in order to resolve the wavelength dependence of the solar flux, of the Rayleigh scattering cross section, and of the absorption coefficients of the gas and cloud absorption features. Spectral intervals occupied by infrared vibration-rotation bands of gases are further subdivided into $2 \mathrm{~cm}^{-1}$ intervals to improve the resolution of the band profiles and the accuracy of the product rule (Goody and Yung 1989), which is used to combine absorption by two or more gases that absorb in the same spectral interval. Absorption cross sections for $\mathrm{O}_{3}$ and $\mathrm{O}_{2}$ in the visible and UV are taken from DeMore et al. (1992).

Solar fluxes at the top of the atmosphere are measured by the SOLSTICE instrument onboard UARS (Rottman et al. 1993) at wavelengths shorter than $420 \mathrm{~nm}$. We use the values at $1 \mathrm{AU}$ averaged for the periods listed in Table 2 and scale these averages to the appropriate Earth-Sun distance in the middle of each period. Between 420 and $800 \mathrm{~nm}$ and beyond $800 \mathrm{~nm}$, we use fluxes from WMO (1986) and Thekaekara et al. (1969), respectively. The SOLSTICE-measured solar fluxes lead to solar heating rates that are typically a few percent higher than the WMO-based values, as shown in Fig. 1.

\section{b. Infrared cooling}

Absorption and emission within the strong $\mathrm{CO}_{2}$ 15$\mu \mathrm{m}$ band and the $\mathrm{O}_{3} 9.6-\mu \mathrm{m}$ band dominate the thermal flux divergences and cooling rates at most stratospheric levels. A variety of other gases included in the model also absorb and emit thermal radiation, but their contributions to the stratospheric cooling rates are much smaller. High-altitude tropospheric clouds affect the thermal cooling rates within the lower stratosphere by modulating the upward flux of thermal radiation from the warm surface and lower troposphere, but the relatively low single-scattering albedo of water droplets and ice crystals at thermal infrared wavelengths reduces the importance of multiple scattering. This substantially decreases the complexity and computational expense of the thermal radiative modeling methods.

To account for the thermal radiative processes listed above, the radiative transfer model includes absorption by gases $\left(\mathrm{H}_{2} \mathrm{O}, \mathrm{CO}_{2}, \mathrm{O}_{3}, \mathrm{~N}_{2} \mathrm{O}, \mathrm{CH}_{4}, \mathrm{O}_{2}, \mathrm{NO}_{2}\right)$ and clouds, but neglects multiple scattering. A Voigt quasirandom model (Crisp 1989, 1990) is used to find gas transmission functions within spectral intervals occupied by vibration-rotation bands. The method described by Roberts et al. (1976) is used for water vapor con- 
tinuum absorption. Clouds and aerosols are treated as continuum absorbers within each thermal infrared spectral interval and their transmission is obtained from Beer's law. The solution to the thermal equation of transfer is similar to that described by Crisp [1989, Eqs. (5) $-(9)$ ], except that the surface boundary condition was modified to include a nonunit emissivity and a temperature gradient between the surface and the first atmospheric level above the surface [Crisp 1990, Eq. (14)]. In the calculations reported here, the twostream, diffusivity-factor approach for approximating the upward and downward thermal fiuxes is used.

The thermal spectrum between 5.26 and $250 \mu \mathrm{m}$ is divided into 95 spectral intervals in order to resolve gas absorption bands and the wavelength dependence of the Planck function. As in the solar flux calculation, spectral intervals occupied by gas vibration-rotation bands are further subdivided into $2 \mathrm{~cm}^{-1}$ intervals to better resolve band contours and to improve the accuracy of the product rule. Gas absorption line parameters at infrared wavelengths are taken from the 1992 edition of the HITRAN database (Rothman 1992).

For completeness, somewhat detailed treatments of surface albedo and of tropospheric clouds, based on climatological data, are included in the radiative transfer calculations of both solar and infrared heating. These details are given in the appendix.

The high accuracy of our thermal infrared code under clear-sky conditions is illustrated in Fig. 2. This figure also shows that at pressures less than $\sim 10 \mathrm{hPa}$ computing the clear-sky net radiative heating with three radiative gases $\left(\mathrm{H}_{2} \mathrm{O}, \mathrm{CO}_{2}\right.$, and $\left.\mathrm{O}_{3}\right)$ and a single surface albedo of 0.3 produces a small relative error. That is, the other gases as well as tropospheric clouds and the distribution of surface albedo will be most important in the lower stratosphere where the net diabatic heating is small.

Perhaps a more important effect that should be included in the radiative calculations is provided by the presence of Mt. Pinatubo aerosols in the early UARS period. In Fig. 3 the heating effects due to aerosols are shown for four selected profiles spanning a range of times and locations. The main effect is in the thermal cooling rates, which are diminished (in absolute values) and in the lower stratosphere are reversed by the absorption of the upwelling radiation from the troposphere. The magnitude of this effect is somewhat larger than the results of previous studies (Kinne et al. 1992; Kinnison et al. 1994). For example, Kinnison et al. estimate a maximum change in the zonally averaged thermal cooling near the equator of $+0.27 \mathrm{~K} \mathrm{day}^{-1}$ at $25 \mathrm{~km}$ in October 1991, which is less than our peak value of $+0.47 \mathrm{~K} \mathrm{day}^{-1}$ at $23 \mathrm{~km}$ in the tropical profile of January 1992 (in the zonal mean, our peak value is $+0.42 \mathrm{~K} \mathrm{day}^{-1}$ ). Kinnison et al. also note that for a pure sulphate composition the solar-heating effects of aerosol are negligible, due to negligible absorption in the visible part of the spectrum. Our results confirm this finding, with the caveat that the treatment of non-
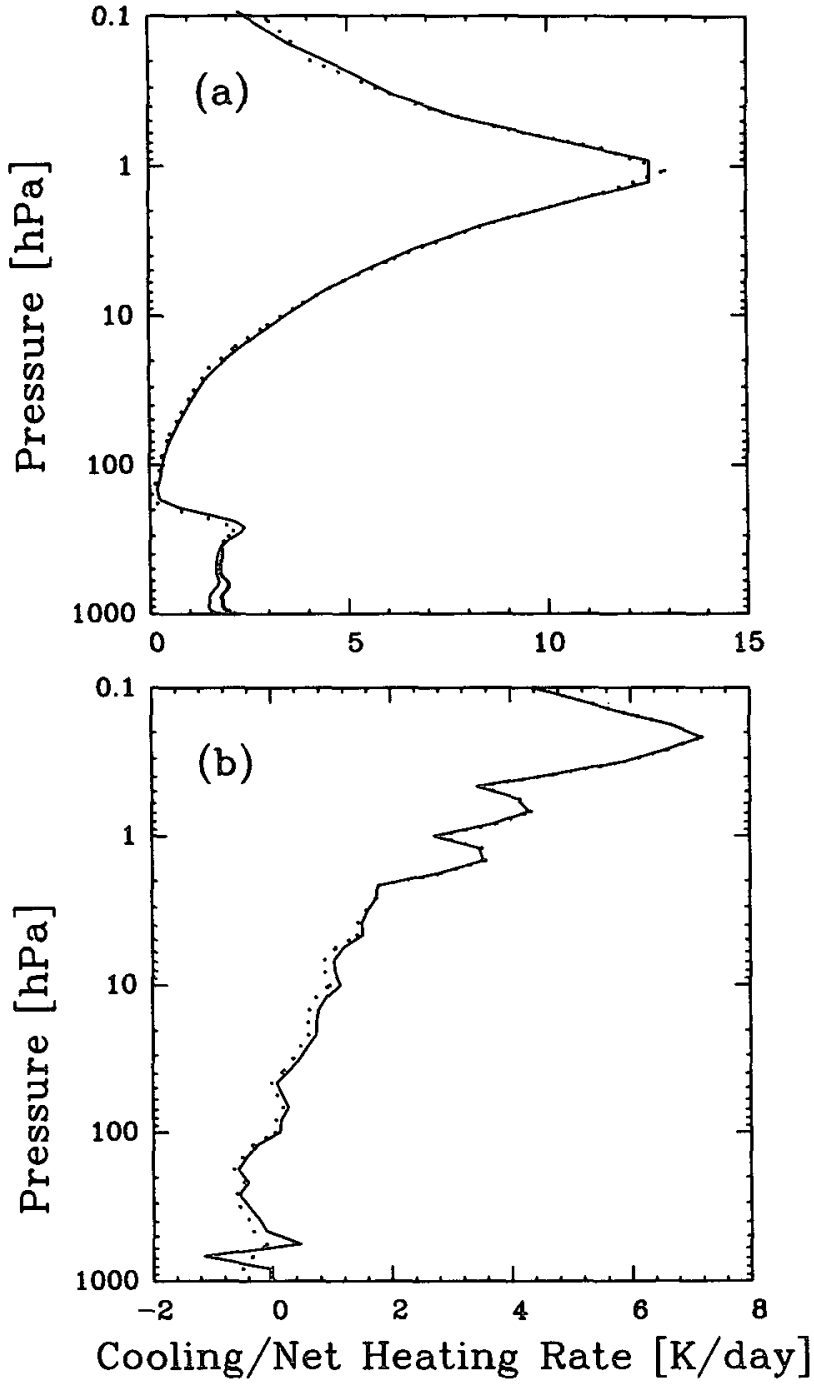

Fic. 2. (a) A comparison of thermal cooling rates in the spectral region between 5.26 and $250 \mu \mathrm{m}$, computed by means of a line-byline model (solid line) and the radiative model described in the text (dotted line). The line-by-line model is described in Bell and Crisp (1993). The model atmosphere is the ICRCCM atmosphere (Luther and Fouquart 1984) with three absorbing gases $\left(\mathrm{CO}_{2}, \mathrm{O}_{3}\right.$, and $\left.\mathrm{H}_{2} \mathrm{O}\right)$ and the calculations have been performed for clear-sky conditions. (b) A comparison of net heating rates for clear-sky conditions with three gases (solid line) and cloudy conditions with seven gases (dotted line). The model atmosphere is the $30^{\circ} \mathrm{N}$ average for 19-26 July 1992, as observed by MLS.

gray gas absorption (in the near-IR) in the presence of multiple scattering is not rigorous in our radiation code.

The results shown in Fig. 3 illustrate a couple of other points. First, the radiative effects of Mt. Pinatubo aerosols rapidly diminish in time; for example, in July 1992 there was no aerosol heating at high northern latitudes and the peak tropical heating rates were half of those in January 1992. Second, the radiative effects are confined to pressures greater than $10 \mathrm{hPa}$, with the al- 


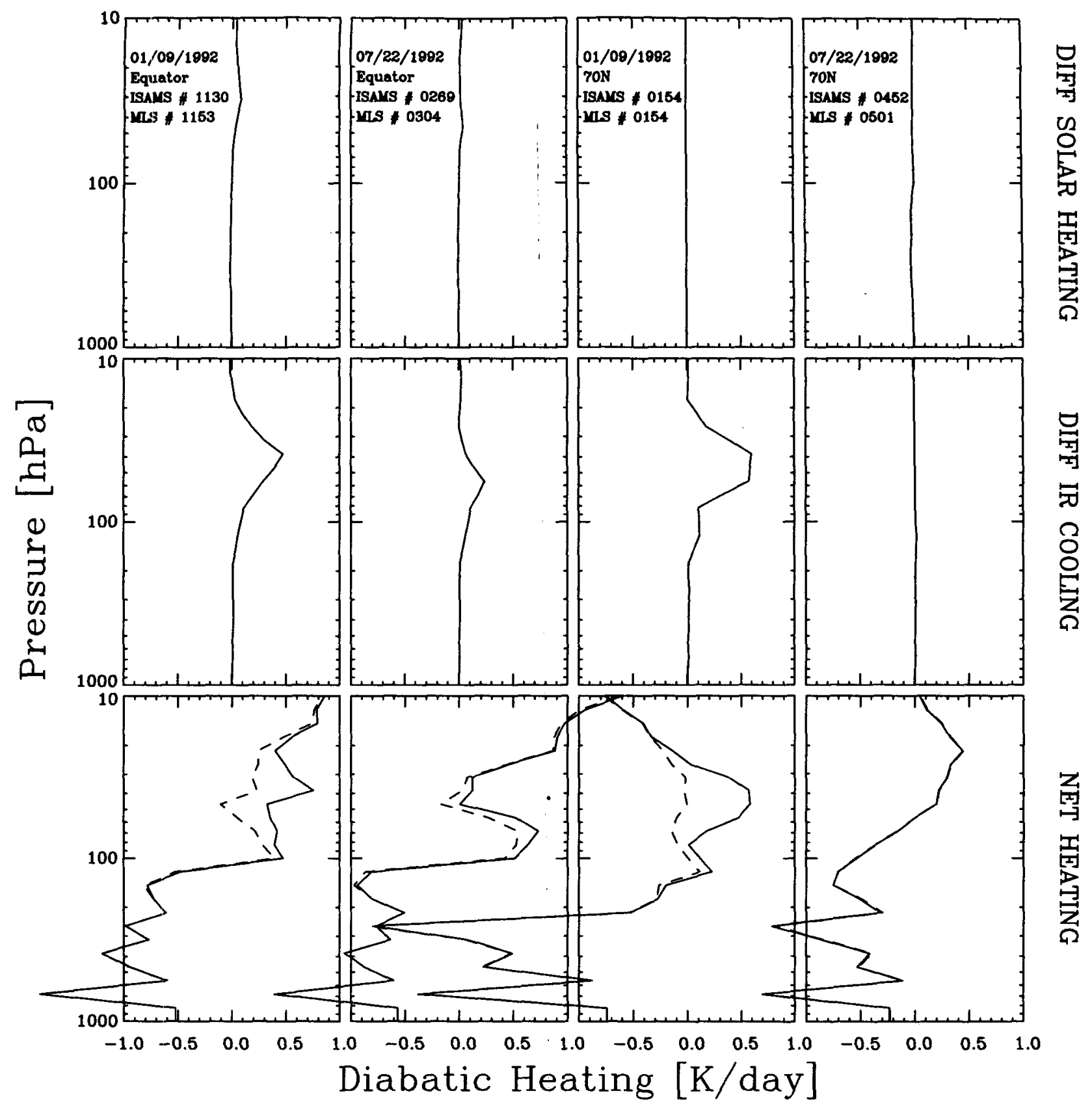

FIG. 3. Radiative effects of Mt. Pinatubo aerosols. The solid lines in the top and middle panels show the differences in diurnally averaged solar heating and thermal cooling, respectively, between cases with and without aerosols (Pinatubo-no Pinatubo). The solid and dashed lines in the lower panels are for net heating with and without aerosols, respectively. The dates, latitudes, and profile numbers (ISAMS for aerosol and temperature, MLS for ozone and water vapor) are given in the upper panels. The distributions of other gases, tropospheric cloud cover, and surface albedo have been set to the corresponding zonal averages. The alternating layers of net heating in the troposphere reflect the presence of tropospheric clouds.

titude of maximum heating descending with time due to droplet sedimentation.

\section{Residual circulation}

The net diabatic heating rates $\bar{Q} e^{-\kappa z / H}$ are obtained as the sum of solar heating and infrared cooling rates, calculated in the manner described in section 4. Given $\bar{Q}$, the vertical and meridional components of the residual circulation $\left(\bar{v}^{*}, \bar{w}^{*}\right)$ are computed from Eqs. (4) and (5). The $\partial \bar{T} / \partial t$ term has been computed by finite differencing in time (between the end days in each averaging period) of the $\bar{T}$ fields obtained by zonal av- 
eraging of level 3AL data (for the south-looking averaging period of 25 January 1994, which consists of just one day of data, the distribution of $\partial \bar{T} / \partial t$ has been set to zero). For the short periods chosen in this study, $\partial \bar{T} / \partial t$ computed in this manner is occasionally quite large, especially in winter. An extreme example is the period 21-25 September 1991, when $\partial \bar{T} / \partial t$ reaches a few $\mathrm{K} \mathrm{day}^{-1}$ in the middle stratosphere at extreme southern latitudes. A more typical distribution of $\partial \bar{T} /$ $\partial t$ (for the period 1-17 February 1993) is shown in Fig. 4b. As can be seen (cf. with Fig. 4a, which shows the distribution of net diabatic heating), even for this "typical" period $\partial \bar{T} / \partial t$ is not negligible, especially in the wintertime lower stratosphere and in the summer hemisphere (where the atmosphere is close to radiative equilibrium and thus $\bar{Q} \approx 0$ ). However, $\partial \bar{T} / \partial t$ decreases when longer time averages are considered and this needs to be taken into account when the resulting residual circulation is to be used in applications such as two-dimensional photochemical modeling (where one is usually interested in monthly mean fields ).

Without global measurements of meridional and vertical winds, the eddy heating term $\bar{E}$ cannot be calculated directly. The authors have employed two methods to estimate the contribution to $\bar{E}$ from planetary-scale eddies. In the first method, this term has been computed from the three-dimensional wind fields provided by the U.K. Meteorological Office and produced through a data assimilation procedure applied to conventional meteorological data, including data from the NOAA TIROS-N series of polar orbiter satellites (Swinbank and O'Neill 1994). At present, the vertical velocity fields are available beginning on 28 August 1992. In the second method, $\bar{E} e^{k z / H}$ has been approximated by the formula

$$
\begin{aligned}
-\frac{1}{\rho} \frac{\partial}{\partial z} & {\left[\rho\left(\overline{v^{\prime} \theta^{\prime}} \frac{1}{a} \frac{\partial \bar{\theta} / \partial \phi}{\partial \bar{\theta} / \partial z}+\overline{w^{\prime} \theta^{\prime}}\right)\right] } \\
& =-\frac{1}{\rho} \frac{\partial}{\partial z}\left[\frac{\rho}{\partial \bar{\theta} / \partial z}\left(\overline{Q^{\prime} \theta^{\prime}}-\frac{1}{2} \frac{\partial \overline{\theta^{\prime 2}}}{\partial t}\right)\right],
\end{aligned}
$$

which can be obtained from the linearized thermodynamic equation, provided the terms in that equation representing advection by zonally averaged meridional and vertical winds are negligible. The evaluation of the right-hand side of the above equation requires the knowledge of the three-dimensional field of net diabatic heating. We have chosen for this purpose a somewhat simpler, but much faster radiative code described by Olaguer et al. (1992) and the three-dimensional synoptic maps of ozone, temperature, and water vapor produced by means of the technique described by Elson and Froidevaux (1993) (see section 3). That technique starts with a coordinate system rotation from the longitude/time domain to an $r / s$ domain. The maps used here depart slightly from those described by Elson and Froidevaux in that Fourier transforms are calculated for $s$ only. Maps (one time, many longitudes) are made by calculating inverse transforms in the $s$ domain but interpolation is used for the orthogonal coordinate, $r$. These maps are supplemented at all longitudes by the zonally averaged distributions of minor gases (obtained in the manner described in section 3 ). The three-dimensional fields of net diabatic heating are then computed for each day in a given averaging period and the right-hand side of Eq. (7) is evaluated for each day using the field of $\partial T / \partial t$ obtained by finite differencing in time of the synoptic maps of $T$ (i.e., $\partial T / \partial t$ is assumed constant over a given averaging period). The results are then averaged in time.

The distributions of $\bar{E}$ obtained by the two methods for the period of 1-17 February 1993 are shown in Figs. $4 \mathrm{c}$ and $4 \mathrm{~d}$. This period was chosen for illustrative purposes, since the atmosphere was highly disturbed at that time and the corresponding values of $\bar{E}$ are particularly large. As can be seen, at high winter latitudes $\bar{E}$ is not small relative to net diabatic heating (cf. Fig. 4a). However, outside of those latitudes this term is generally smaller than $0.05 \mathrm{~K} \mathrm{day}^{-1}$, and its retention in Eq. (5) changes the distributions of $\left(\bar{v}^{*}, \bar{w}^{*}\right)$ only slightly. Since the main focus of this paper is on the Tropics and because $\bar{E}$ is difficult to estimate with any desired accuracy, we have neglected this term in the subsequent calculations. It is interesting to note that the two methods of calculating $\bar{E}$ give similar results in most of the middle atmosphere, demonstrating in particular the smallness of this term outside of the winter hemisphere. The disagreement between the two methods in the winter hemisphere may reflect the inadequacy of approximation (7) under disturbed conditions, the uncertainties in assimilated fields (e.g., $w^{\prime}$ ), or differences in the computed diabatic heatings due to different algorithms and inputs.

Equations (4) and (5) are solved by means of a numerical approach developed by R.-L. Shia and M. Santee, in which a streamfunction $\chi^{*}$ is introduced

$$
\begin{aligned}
& \bar{v}^{*}=-\frac{1}{\cos \phi} e^{z / H} \frac{\partial}{\partial z}\left(e^{-z / H} \chi^{*}\right), \\
& \bar{w}^{*}=\frac{1}{a \cos \phi} \frac{\partial \chi^{*}}{\partial \phi},
\end{aligned}
$$

and the thermodynamic equation is differentiated with respect to latitude [a detailed description of this method is given by Santee and Crisp (1995)]. The resulting streamfunction equation is solved by a matrix inversion technique, with the residual meridional velocity $\bar{v}^{*}$ set to zero at the poles by specifying the residual streamfunction $\chi^{*}=0$ there. This scheme avoids numerical instabilities, even with coarse latitudinal resolution. By solving the thermodynamic equation to within an additive constant, this approach assumes that systematic errors in the computation of the radiative heating and cooling are functions of height (pressure) only and not of latitude. 


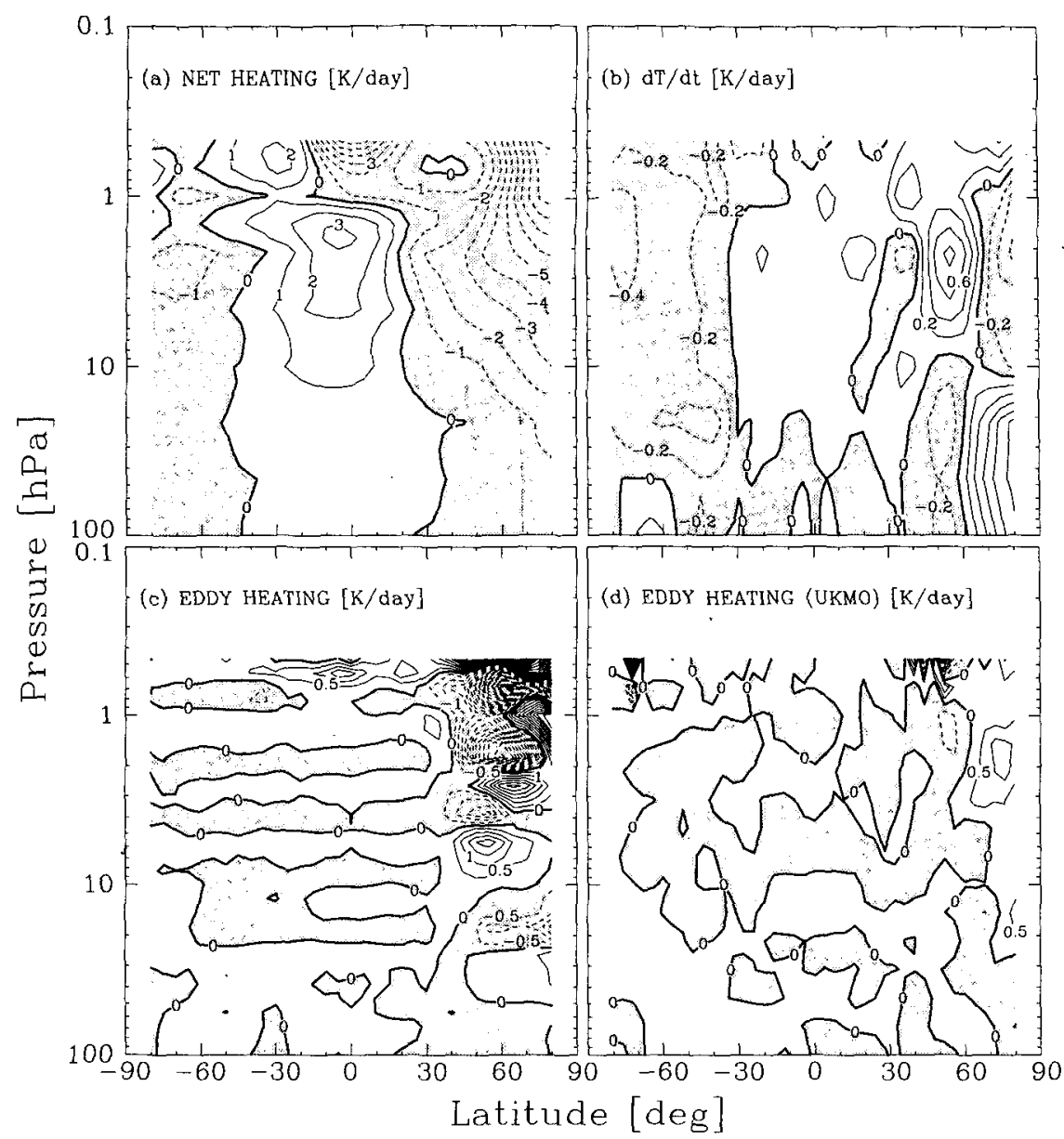

FIG. 4. Latitude-height sections of (a) net diabatic heating, (b) temperature tendency $\partial \bar{T} / \partial t$, (c) eddy heating computed from the right-hand side of Eq. (7) (multiplied by $e^{-\kappa z / H}$ ), and (d) eddy heating [the second term in Eq. (5) multiplied by $e^{-\frac{\mathrm{K} z / H}{}}$ ] calculated from UKMO meteorological fields. In (a) - (c), the time average is for the periods 1-8 February, 1-17 February, and 10-17 February, 1993 for the latitude bands $80^{\circ}-30^{\circ} \mathrm{S}, 30^{\circ}-30^{\circ} \mathrm{N}$, and $30^{\circ}-80^{\circ} \mathrm{N}$, respectively. In (d), the time average is for the period 1-17 February, 1993. Contour intervals are $1 \mathrm{~K} \mathrm{day}^{-1}$ in (a), $0.2 \mathrm{~K} \mathrm{day}^{-1}$ in (b), and $0.5 \mathrm{~K} \mathrm{day}^{-1}$ in (c) and (d), with regions of negative values shaded. The 3-D field of net heating used in computing the distribution shown in panel $c$ has been obtained from MLS data by means of the radiative code described by Olaguer et al. (1992) (see text for details).

The upper and lower boundary conditions are introduced by replacing the centered finite-difference formulas for the vertical derivatives [Eqs. (A2) and (A3) in Santee and Crisp (1995)] by backward and forward formulas, respectively. This assumes $\partial^{2} \chi^{*} / \partial z^{2}=0$ and is akin to a no-stress condition (which requires $\partial \bar{v}^{*} / \partial z=0$ ). This approach makes it possible to compute $\bar{w}^{*}$ at those boundaries self-consistently. While $\bar{w}^{*}$ so obtained may not account for the total mass flux at $100 \mathrm{hPa}$, especially in the Tropics (where deep convection can contribute to diabatic heating), it is still an interesting quantity to compare with the values from Garcia and Solomon (1983), Holton (1990), and Rosenlof and Holton (1993). We plot $\bar{w}^{*}$ at $100 \mathrm{hPa}$, averaged for each of the four seasons, as a function of latitude in Fig. 5. Our method of com- puting $\bar{w}^{*}$ should give better results during the equinox seasons, when the "downward control principle" used by Holton (1990) and Rosenlof and Holton (1993) is less reliable [Garcia and Solomon (1983) imposed $\bar{w}^{*}$ externally at $100 \mathrm{hPa}$ ]. However, as discussed earlier, uncertainties may still be large at $100 \mathrm{hPa}$, given uncertainties and the nonsimultaneity of our input fields and the neglect of aerosols in the early UARS period. The values of the extratropical downward mass flux at $100 \mathrm{hPa}$, averaged for the four seasons, are listed in Table 3, together with the values from Rosenlof and Holton. In comparing the two sets of values, one should bear in mind that they refer to different periods (Rosenlof and Holton computed a 10year climatology for 1979-1989) and, thus, there is a possibility of interannual and interdecadal variability. Our 


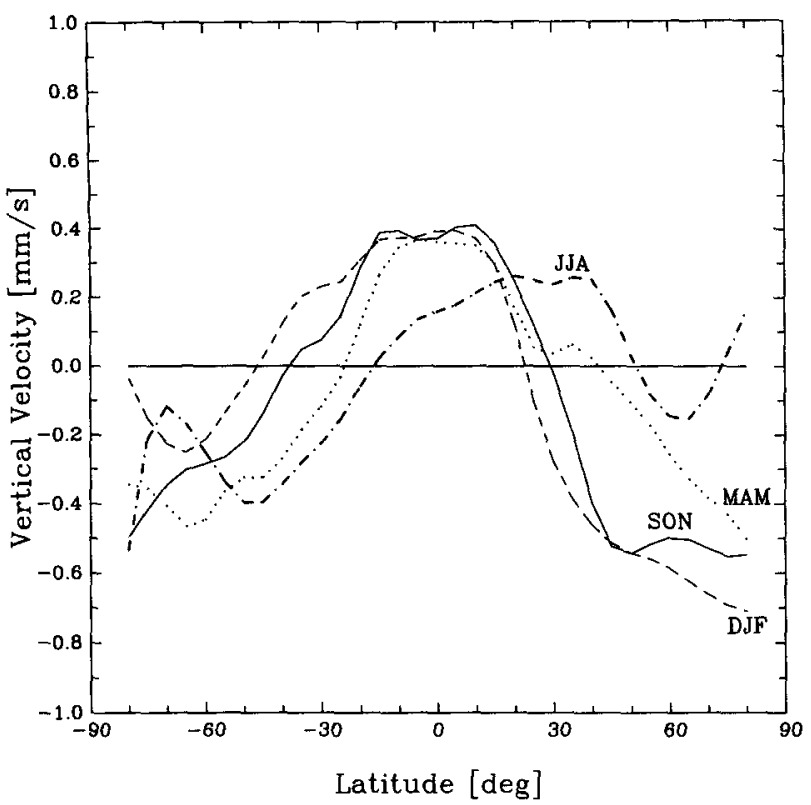

Fig. 5. The residual vertical velocity at $100 \mathrm{hPa}$. Solid line: September-October-November (the average for the yaws $1,2,11,12$, 13, 21, 22, and 23); Dashed line: December-January-February (yaws 3, 4, 5, 14, 15, 24, and 25); dotted line: March-April-May (yaws 6, 7, 16, 17, 18, 26, 27, and 28); dashed-dotted line: JuneJuly-August (yaws 8, 9, 10, 19, 20, 29, and 30). See Table 2 for a list of yaws and their averaging periods.

wintertime and summertime values are larger and smaller, respectively, than those of Rosenlof and Holton, but their sum, and thus the tropical upward mass flux, are similar in the two studies.

In the following, all distributions will be shown only between 100 and $0.46 \mathrm{hPa}$, with the upper boundary being determined by the quality of MLS data. The extension of the calculations to pressures less than $0.46 \mathrm{hPa}$ (where our temperatures relax to the a priori climatology in the MLS inversion algorithm) is necessary in order to avoid spurious results at the upper boundary. We have verified that with a given distribution of diabatic heating, the circulation at pressures greater than $0.46 \mathrm{hPa}$ changes little when the upper boundary on the streamfunction equation is placed anywhere at pressures less than $0.2 \mathrm{hPa}$. The circulation in the lowermost stratosphere is clearly sensitive to the choice of the lower boundary condition at $100 \mathrm{hPa}$; we feel that our condition is more physical than a no-flow condition $\left(\bar{w}^{*}=0\right)$.

In addition to the residual circulation, the zonally averaged zonal velocity at latitudes greater than $5^{\circ}$ is computed using the gradient wind relationship - that is, Eq. (2) with $\mathscr{g}=0$-and the geopotential fields computed from Eq. (3) using MLS temperatures and the $100-\mathrm{hPa}$ reference level obtained from the National Meteorological Center [in solving Eq. (2), we chose the root with the smaller absolute value of $\bar{u}$ ]. The zonal wind at the equator is obtained by interpolation, as was done by Hitchman and Leovy (1986). Given the three TEM velocity components, it is possible to calculate the right-hand side of Eq. (1) and thus the forcing of the circulation (Hartmann 1976; Shine 1989). This forcing is the sum of contributions from planetary and small-scale waves. It is thought that the former dominate in the stratosphere, but their contribution $(1 / \rho a \cos \phi) \nabla \mathscr{F}$ cannot be separately determined in the present approach.

Figures 6-10 show the distributions of the zonally averaged gradient wind, the mass-weighted streamfunction $X^{*} \equiv 2 \pi a \rho_{s} e^{-z / H} \chi^{*}$ (where $\rho_{s}$ is the reference density at $1000 \mathrm{hPa}$ ), the meridional and vertical components of the residual circulation, and the zonal momentum residual, respectively. The time derivative of gradient wind required for the calculation of the momentum residual is obtained by differentiating the gradient wind equation with respect to time and using the fields of $\partial \bar{T} / \partial t$ and of the geopotential height tendency at $100 \mathrm{hPa}$, both computed by finite differencing. The gross features of the circulation fields shown in Figs. 6-10 are quite similar in the three UARS years, but a close inspection reveals substantial interannual variability. Particular features for each of the five fields will be discussed in turn. The figures for these fields are organized so that time increases from top to bottom and in successive columns. Since our fields are averaged around UARS "'months" defined by the spacecraft yaw events, and there are 10 of these in a given year, each five-panel column represents half a year and thus one cycle of the semiannual oscillation. The annual variation can be seen by contrasting adjacent columns. The top two rows are essentially the equinoctial periods and early fall and spring, while the bottom two rows are solstitial periods and early winter and summer. Note that the averaging periods are different by a few days from year to year (see Table 2), as the UARS orbit changes slightly.

\section{a. $\bar{u}$}

Many of the expected hemispheric differences are readily seen in Fig. 6. Wintertime westerlies are much

TABLE 3. Extratropical downward mass flux at $100 \mathrm{hPa}$, in units of $10^{8} \mathrm{~kg} \mathrm{~s}^{-1}$, calculated using MLS data and the radiation code, compared with results from Rosenlof and Holton (1993) obtained using UKMO data and the downward control method. Note: The extratropics are defined as the region poleward of the lowest latitude at which the vertical velocity is downward (see Fig. 5).

\begin{tabular}{lrrrrr}
\hline & \multicolumn{2}{c}{ NH } & & \multicolumn{2}{c}{ SH } \\
\cline { 2 - 3 } \cline { 5 - 6 } & MLS & UKMO & & MLS & UKMO \\
\hline DJF & 102.7 & 80.6 & & 13.9 & 33.4 \\
MAM & 25.3 & 45.7 & & 59.5 & 30.7 \\
JJA & 4.5 & 25.7 & 64.3 & 30.1 \\
SON & 79.3 & 42.7 & 34.1 & 27.6 \\
\hline
\end{tabular}




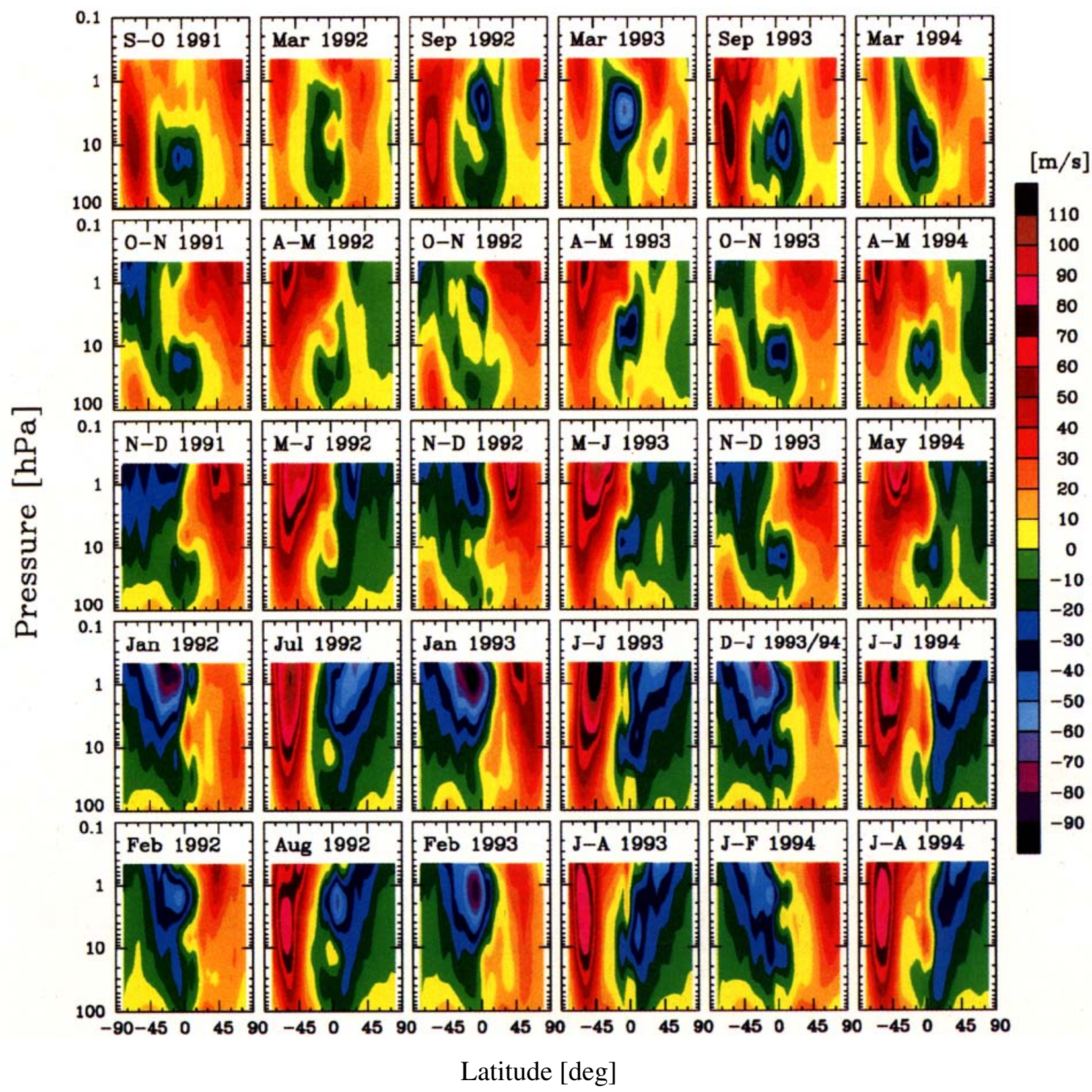

Fig. 6. Latitude-height sections of the zonal wind.

stronger in the Southern Hemisphere. As a consequence of minor stratospheric warmings, the Northern Hemisphere westerlies are particularly weak in January 1992 and 1994 and in February 1993. The final warming (i.e., the seasonal transition from westerlies to easterlies at high latitudes) in the Southern Hemisphere is well under way by the end of October. In the north, the zonally averaged westerlies are already weak at the spring equinox. In January, a strong easterly jet with velocities in excess of $90 \mathrm{~m} \mathrm{~s}^{-1}$ is present at southern subtropical latitudes in the lower mesosphere and upper stratosphere. In February, a residual core of easterlies resides around $2 \mathrm{hPa}$ at $10^{\circ} \mathrm{S}$. Similarly strong easterlies were computed at the same location by Hitchman (1985) for January 1979, based on LIMS temperatures. In his study, the residual core of easterlies in February 1979 resides around $7 \mathrm{hPa}$ at $10^{\circ} \mathrm{S}$. Our study shows that strong easterlies are also present in the lower mesosphere and upper stratosphere at northern subtropical latitudes in July, but the maximum velocities are somewhat reduced compared with their January counterpart. Also note the signature of the quasi-biennial oscillation 


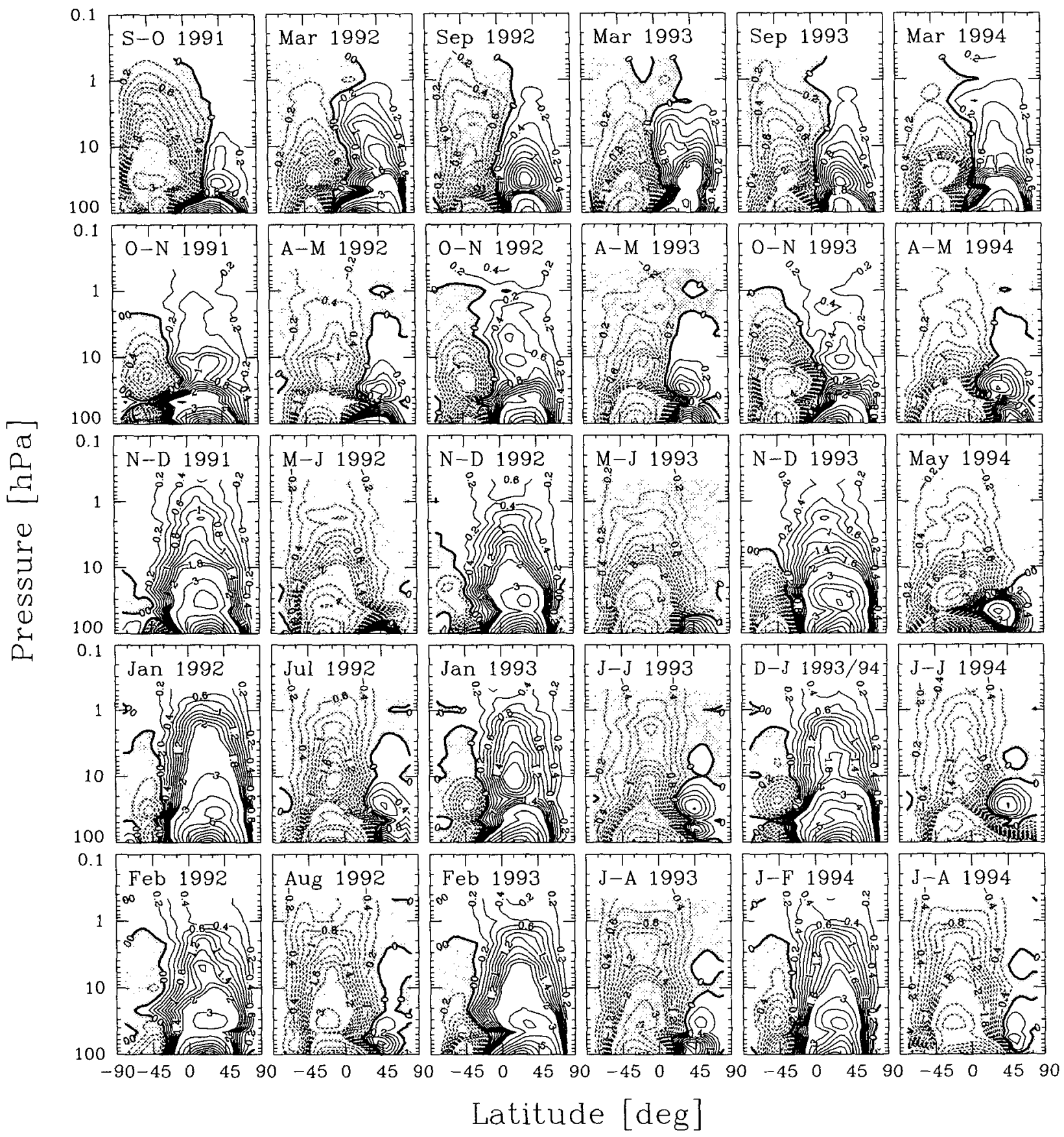

FIG. 7. Latitude-height sections of the mass-weighted streamfunction $X^{*} \equiv 2 \pi a \rho_{x} e^{-z / H} \chi^{*}$ (in units of $10^{9} \mathrm{~kg} \mathrm{~s}^{-1}$ ). The contour interval is 0.2 and 1.0 for absolute values lower and greater than 2.0 , respectively. The zero-line is thicker and shading denotes areas of counterclockwise flow.

in the low-latitude $\bar{u}$ field, as a core of maximum easterlies around $10 \mathrm{hPa}$ in 1991 weakens, reappears higher up in 1992 and descends with time.

\section{b. $X^{*}$ and $\bar{v}^{*}$}

The Brewer-Dobson circulation (upwelling in lowto midlatitudes, downwelling at high latitudes) can be seen in the distribution of $X^{*}$ in Fig. 7. However, the summertime downward cell is very small and not always simply connected. In March, the southern branch of the Brewer-Dobson circulation intrudes into the Northern Hemisphere around the stratopause.

In the winter hemisphere, $\bar{v}^{*}$ is large at subtropical and midlatitudes around the stratopause (Fig. 8), form- 


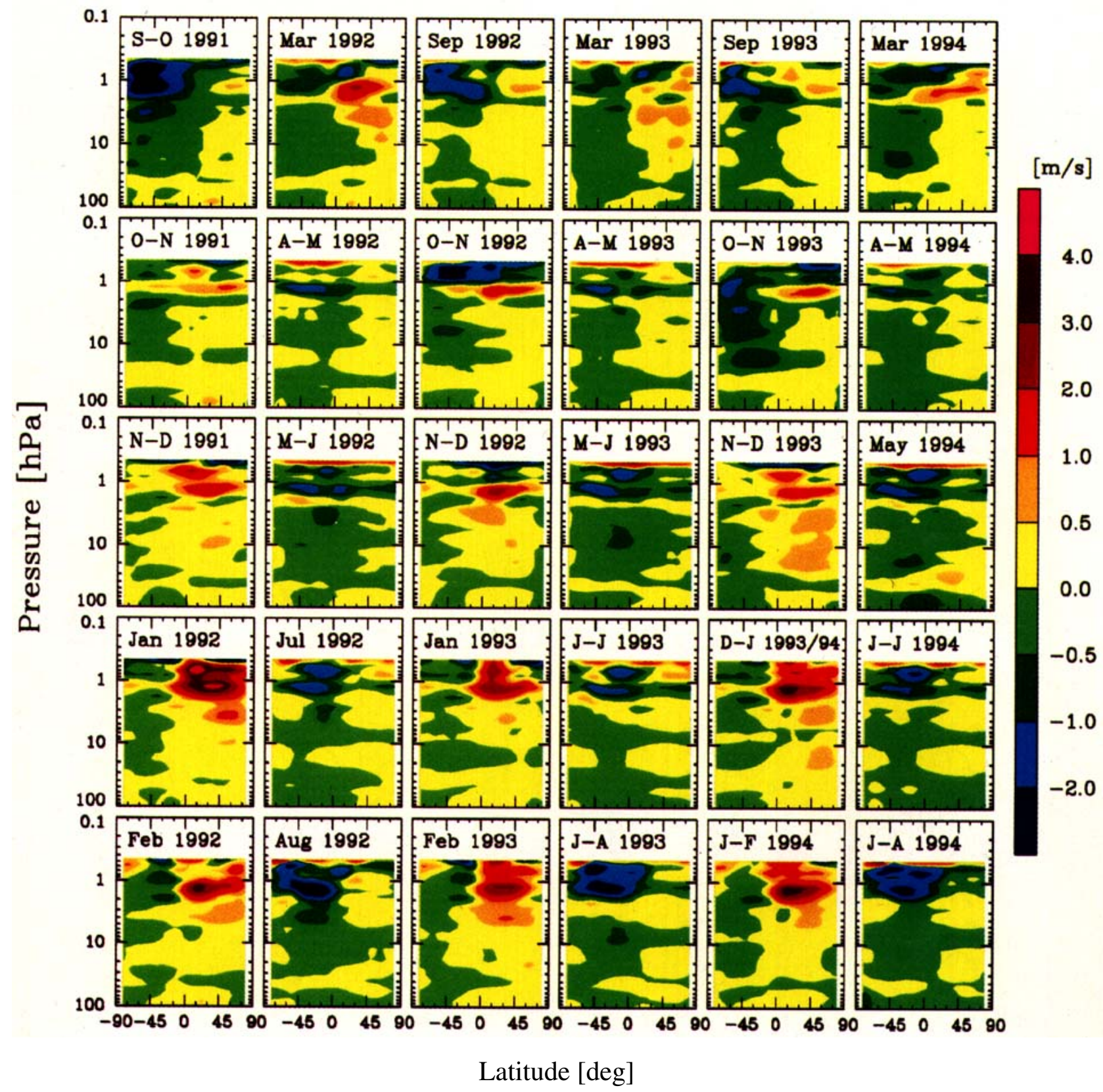

FIG. 8. Latitude-height sections of the meridional component of the residual circulation $\bar{v}$.

ing a feature with two maxima in the upper stratosphere and lower mesosphere. The peak values of $\bar{v}^{*}$ in January are almost a factor of 2 higher than those diagnosed for July. Our peak values in the mesospheric portion of this feature in January 1992 (in excess of 4 $\mathrm{m} \mathrm{s}^{-1}$ ) are similar to those of Hitchman and Leovy (1986), who diagnosed a similar feature in the lower mesosphere from LIMS data (see their Fig. 16), but did not diagnose the upper stratospheric maximum. A hint of a lower mesospheric maximum is also present in the other LIMS-based studies by Solomon et al.
(1986) and Gille et al. (1987), but their peak values are roughly a factor of 2 lower than ours. A wintertime lower mesospheric maximum was also present in the climatological studies of Rosenfield et al. (1987) and Callis et al. (1987). As pointed out by Callis et al., whether or not strong poleward flows are obtained depends, especially in the polar night, on the use of a detailed infrared cooling code and they would not be seen if a Newtonian code were used. In January and July, there is a weak (less than $0.5 \mathrm{~m} \mathrm{~s}^{-1}$ ) equatorward flow in the summer hemisphere around 8 and $50 \mathrm{hPa}$. 


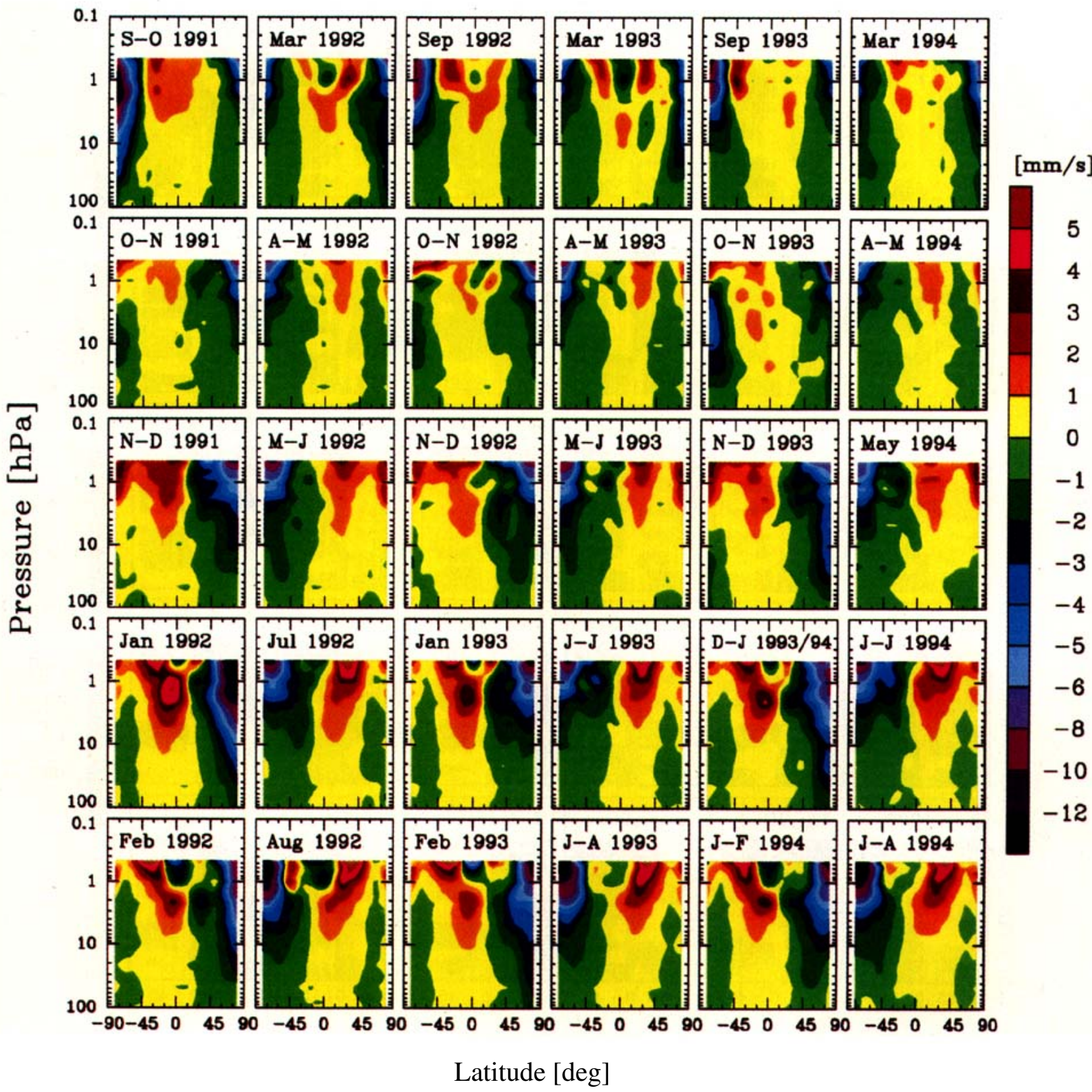

Fic. 9. Latitude-height sections of the vertical component of the residual circulation $\bar{w}^{*}$.

The existence of such flow was first noted and its implications discussed by Choi and Holton (1991), but in our case it may also, at least at $46 \mathrm{hPa}$, be an artifact of the low tropical heating rates at this level (see caption to Fig. 12); this will be investigated in a future paper.

c. $\bar{w}^{*}$

The very strong downwelling at high latitudes in the winter hemisphere (Fig. 9) is probably connected to a mesospheric cross-equatorial cell (Leovy 1964). Strong (in excess of $12 \mathrm{~mm} \mathrm{~s}^{-1}$ ) downward velocities at high latitudes in the wintertime lower mesosphere are a feature our study shares with that of Solomon et al. (1986). Note that in the mesosphere, the maximum downward velocities in the Southern Hemisphere in August are larger than their counterparts in the Northern Hemisphere in February. On the other hand, in the stratosphere, wintertime downward velocities are usually larger in the north, with significant interannual variability, when the greater wave activity during 


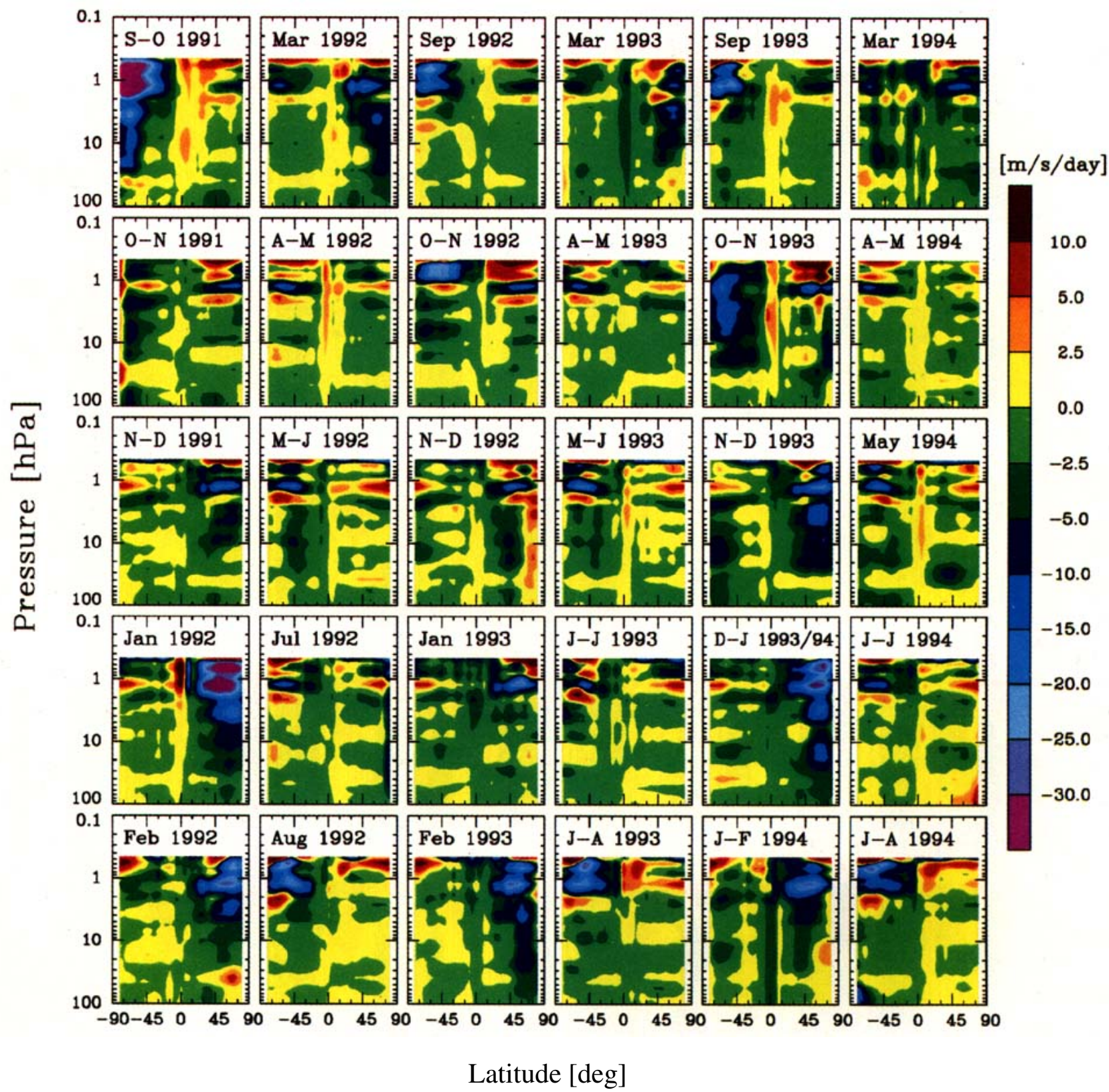

Fig. 10. Latitude-height sections of the zonal momentum residual [the left-hand side of Eq. (1)].

northern winter leads to larger departures from radiative equilibrium and thus to larger diabatic cooling rates. These departures are greatest during winter periods with strong stratospheric warming events. This is reflected for the middle stratosphere in Fig. 9, where significant wintertime polar downwelling extends well below $5 \mathrm{hPa}$ in the early January to mid-February 1992, mid-February 1993, and December to January 1993/94 averaging periods (Table 2 ). In the lower stratosphere, downward velocities are smaller than $1 \mathrm{~mm} \mathrm{~s}^{-1}$ during the southern winters 1992 and 1993 (September 1991 is a special case, when the very strong residual veloc- ities in high southern latitudes were caused by the unusually large values of $\partial \bar{T} / \partial t$, on the order of a few $\mathrm{K}_{\text {day }^{-1}}$, in the period 21-25 September 1991; whether such large velocities were sustained over a longer period is unclear). Downward velocities in February 1993 exceed $2 \mathrm{~mm} \mathrm{~s}^{-1}$ in high northern latitudes at $50 \mathrm{hPa}$ and are larger than those in February 1992 and 1994 (less than $1 \mathrm{~mm} \mathrm{~s}^{-1}$ at $50 \mathrm{hPa}$ ). Only during the more quiescent northern winter periods (e.g., January 1993) are vertical velocities similar to the fairly repeatable diabatic velocities computed for Antarctic winters. In the lower portions of the stratosphere, win- 


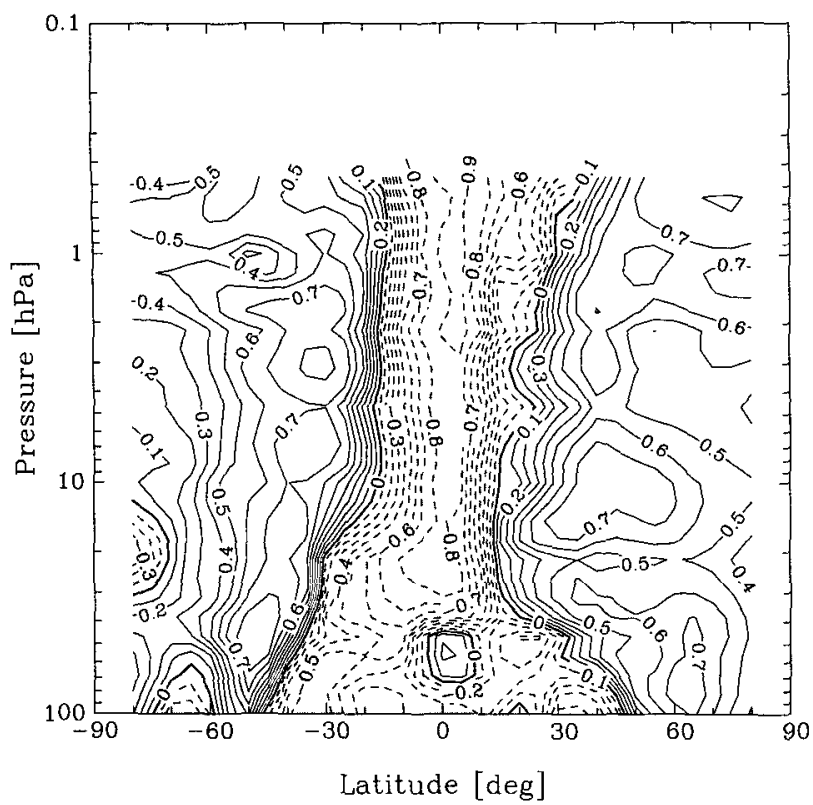

Fig. 11. Correlation coefficient $r$ between $T$ and $\bar{w}^{*}$ calculated from the first three UARS years. Regions of anticorrelation are shaded. Within regions where $|r|>0.5$, the sign of correlation is certain at the $99 \%$ confidence level.

tertime descent maximizes away from the pole (note, e.g., the $-2 \mathrm{~mm} \mathrm{~s}^{-1}$ contour), except during stratospheric warmings. This conforms with theoretical arguments and results from both observational and modeling studies (Schoeberl et al. 1992; Eluszkiewicz et al. 1995), which predict that maximum descent should occur near the vortex edge (the latter can be identified to first order as the core of the polar jet in Fig. 6).

Downwelling at high latitudes occurs during both equinoxes, but is stronger during spring and in the Southern Hemisphere, consistent with the persistence of a well-organized polar vortex and later final warming in the south, as compared to the north. Note, in particular, the large values at high southern latitudes around $10 \mathrm{hPa}$ during the October-November period. In the summertime, high-latitude downward velocities in the stratosphere are always smaller than $0.5 \mathrm{~mm} \mathrm{~s}^{-1}$ and are fairly symmetric between the two hemispheres. This symmetry continues into the fall season. In the upper stratosphere and lower mesosphere, summertime upward velocities maximize in midlatitudes rather than at the pole. This is in contrast to some previous studies (Rosenfield et al. 1987; Shine 1989; Nielsen et al. 1994) and may be important in the simulations of tracers localized near the summer pole (such as nitrogen oxides from the solar proton events modeled by Nielsen et al.).

In the Tropics, a region of downwelling exists in the upper stratosphere and lower mesosphere during northern and southern winters. From December through February, this region expands downward from a level in the mesosphere. This behavior mimics that obtained by Hitchman and Leovy (1986), who computed the residual circulation using LIMS data. A region of downwelling around the tropical stratopause was also computed by Solomon et al. (1986) and Gille et al. (1987), again based on LIMS data. On the other hand, it was not diagnosed in the studies based on climatological data, since the coarse vertical resolution of the climatological temperature fields, as well as the monthly averaging used to obtain those fields, tend to reduce the amplitude of vertical temperature contrasts (Hitchman 1985). As discussed by Hitchman and Leovy, the presence of a region of downwelling around the tropical stratopause is related to the high-temperature phase of the semiannual oscillation. The season of maximum temperatures at the tropical stratopause corresponds to a time of maximum diabatic cooling (since at those altitudes cooling is dominated by the cooling-to-space mechanism), as well as to a time of minimum solar heating (since temperature and ozone are anticorrelated). In a diagnostic calculation, these two effects lead to a maximum in the net diabatic cooling, and thus a maximum in the downward vertical velocities (but see section 6 for a discussion of cause and effect in this case).

\section{d. Zonal momentum residual}

The peak values of the residual (Fig. 10) at mid- and high latitudes during winter (about $-25 \mathrm{~m} \mathrm{~s}^{-1}$ day $^{-1}$ at the stratopause in January) are generally consistent with previous studies (Shine 1989; Choi and Holton 1991), but occur at lower altitudes. In January and July, the residual is mostly negative in the stratosphere, except in the regions of equatorward flow in the summer hemisphere around 8 and $50 \mathrm{hPa}$. Between 10 and 1 $\mathrm{hPa}$, the residual exhibits significant interannual variability during the three northern winters: the values for January 1993 and February 1993 are smaller and larger, respectively, than those for the same month in the other two years. As expected, the momentum residuals are largest at high northern latitudes during the stratospheric warming periods. According to the "downward control principle" (Haynes et al. 1991), this variability leads to interannual variability (discussed in section 5c) in the lower stratospheric vertical velocities. The values of the residual between 10 and $1 \mathrm{hPa}$ are smaller during southern winter. However, they increase as the season progresses from early to late winter and in spring are much larger than their northern counterparts (e.g., cf. the April-May with the October-November periods). This springtime asymmetry is also reflected in the lower stratospheric downward velocities.

\section{SAO and stratospheric transport}

The SAO signal in $\bar{w}^{*}$ discussed in section $5 \mathrm{c}$ has been diagnosed from the observed distribution of tem- 


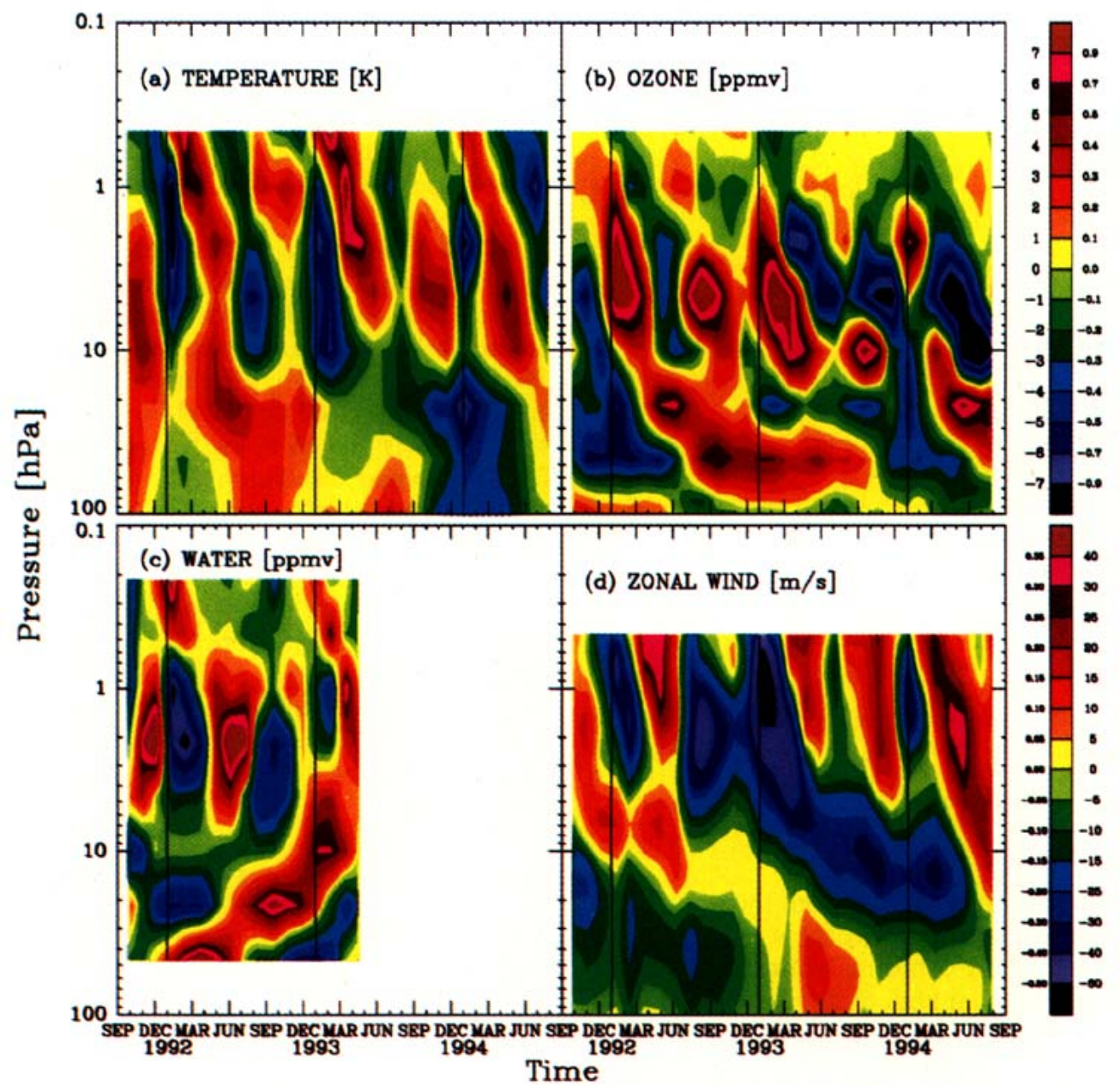

FIG. 12. Zonally averaged equatorial time-height sections of (a) temperature, (b) ozone, (c) water vapor, (d) zonal wind, (e) net diabatic heating, (f) $\bar{w}^{*}$, and (g) $\bar{v}^{*}$. In panels (b) and (c) the time mean has been taken out. Vertical lines indicate year boundaries. The negative (or generally low) heating rates at $46 \mathrm{hPa}$ are artifacts of the neglect of Mt. Pinatubo aerosols (cf. the lower left hand panel in Fig. 3) and of the systematic underestimate in the tropical $\mathrm{O}_{3}$ mixing ratios at $46 \mathrm{hPa}$ in MLS version 3 retrievals (Froidevaux et al. 1994a,b).

perature and ozone. This diagnostic result does not imply, however, a cause and effect relationship between $T$ and $\bar{w}^{*}$. Rather, the distribution of $T$ is a result of dynamical effects (represented by $\bar{w}^{*}$ ) and radiative effects resulting from the annual cycle in the solar heating rates (Andrews et al. 1987). Following Geller et al. (1992), the regions of the middle atmosphere where these two effects dominate can be delineated by computing the correlation coefficient $r$ between $T$ and $\bar{w}^{*}$. The distribution of $r$ for the first three UARS years is shown in Fig. 11. In the stratosphere, this distribution bears a striking resemblance to the distribution computed by Geller et al. from climatological data for 1978-86 (see their Fig. 3). In particular, $T$ and $\bar{w}^{*}$ are strongly anticorrelated in the Tropics and positively correlated at higher latitudes. The boundary between the two regions is very sharp. The tropical anticorrelation implies dynamical control of temperature: rising residual motions give rise to cold temperatures and de- scending motions give rise to warm temperatures. In the extratropics, on the other hand, the temperatures are primarily under radiative control: warm in summer and cold in winter, with the season of cold temperatures coinciding with the season of strong downward $\bar{w}^{*}$. This downward motion causes the temperatures to be higher than they would be in the absence of dynamical effects. Put another way, the seasonal variation of stratospheric temperatures outside the Tropics is dominated by the change in radiative equilibrium temperatures, even as departures from radiative equilibrium are dynamically produced. Our distribution of $r$ differs from that of Geller et al. above the stratopause, with the anticorrelation between $T$ and $\bar{w}^{*}$ extending into the mesosphere at a high confidence level.

The dynamical processes controlling tropical temperatures are still somewhat uncertain. Reed and Vlcek (1969) and Geller et al. argued for an upward effect of the Hadley circulation and its variations, but it was 


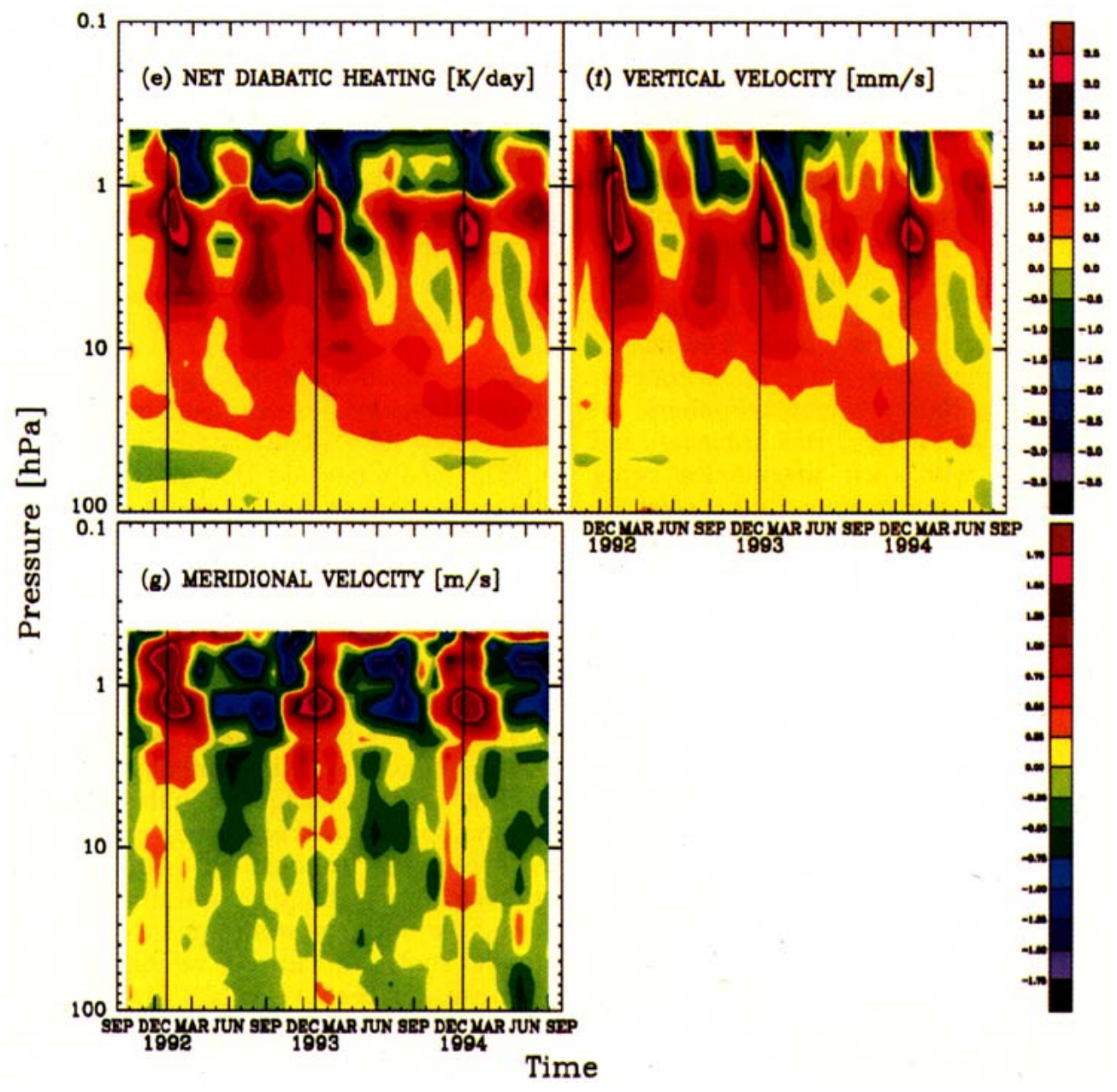

FIG. 12. (Continued)

pointed out by Dunkerton (1989) and Haynes et al. (1991) that extratropical wave forcing may also affect tropical circulation. This latter idea was supported by Iwasaki (1992) and Yulaeva et al. (1994), who studied the causes of the annual cycle in tropical lower stratospheric temperatures. On the other hand, in the tropical upper stratosphere and lower mesosphere, where the largest signal in the temperature variations has a semiannual periodicity, it is likely that the high degree of anticorrelation seen for that region in Fig. 11 is a manifestation of the SAO. With this in mind, we now turn to a discussion of the SAO in the MLS-derived fields.

\section{a. Equatorial SAO}

To better illustrate the semiannual oscillation, in Fig. 12 we show the equatorial time - height sections of temperature, ozone, water vapor, gradient wind, diabatic heating, and the vertical and meridional components of the residual circulation. We do not show a corresponding plot for the momentum residual, for the lack of a reliable method of estimating this quantity at low latitudes. The distributions shown in Fig. 12 are obtained from our zonal-averaging technique described in section 3, with the results interpolated at 5-day intervals, and are thus slightly different from plots obtained from individual profile data (for temperature and the constituents). Froidevaux et al. (1994a) discuss the zonally averaged ozone measurements from MLS in more detail, whereas Ray and Holton (1994) analyze the SAO in MLS-measured temperature and ozone for the first two UARS years. The seasonal variations of water vapor in the tropical lower stratosphere (in particular, the annual cycle seen in Fig. 12c) are discussed by Mote et al. (1995).

The fields of $T, \mathrm{O}_{3}$, and $\bar{u}$, besides exhibiting a clear SAO signal in the upper stratosphere and lower mesosphere, show a possible quasibiennial oscillation (QBO) in the middle and lower stratosphere (especially prominent in $\bar{u}$ ). In fact, a "QBO" signal extends into the upper stratosphere, in the sense that the temperatures there are higher and ozone abundances 
lower in 1993/94 compared with 1992/93. This behavior is reflected in (or, as discussed earlier, is caused by) a QBO-like signal in the time series of $\bar{w}^{*}$, superimposed on a strong SAO signal. Despite the short data record, the authors believe that this may be a genuine QBO-signal rather than a coincidental interannual variability, since the time-height section of $\bar{w}^{*}$ resembles that of the zonal wind. The anti-phase relationship in the SAO signals for ozone and water vapor are consistent with the opposite vertical gradients for the two species above the $\mathrm{O}_{3}$ mixing ratio peak. The annual cycle dominates the time evolution of $\bar{v}^{*}$, except possibly at the highest level shown. Our equatorial upward velocities in the upper stratosphere peak in January and August, respectively, with their magnitudes being smaller in August. This time asymmetry between the two SAO cycles is consistent with forcing by planetary waves, whose activity is greater during northern winter.

Several other features seen in Fig. 12d are worth mentioning. Time-mean easterlies prevail in the stratosphere, reaching a maximum around $2 \mathrm{hPa}$, but in the mesosphere the mean wind is westerly. Our vertical profile (not shown) of the time mean of $\bar{u}$ roughly agrees with the profile presented by Reed (1966) in his pioneering study of the SAO, except that our mesospheric westerlies are even stronger than his, exceeding $20 \mathrm{~m} \mathrm{~s}^{-1}$ at pressures less than $0.46 \mathrm{hPa}$. This equatorial superrotation requires an influx of westerly momentum by waves. Vertically propagating Kelvin waves are a likely candidate for producing mesospheric time-mean and SAO westerlies, although Hitchman (1985) concluded that Kelvin waves observed by LIMS contribute no more than $50 \%$ of the required westerly momentum, thus implying a possible contribution from vertically propagating small-scale gravity waves. A theoretical study of the forcing of the westerly phase of the SAO by Kelvin waves was conducted by Dunkerton (1979). He noted that for a certain range of phase speeds and momentum fluxes at the tropopause, the SAO should be modulated by the QBO, with the SAO westerlies reaching lower altitudes and linking up with the QBO westerlies during the easterly phase of the QBO (the latter being usually defined as the prevailing wind at $30 \mathrm{hPa}$ ). Such is the situation in our study (see Fig. 12d). This qualitative agreement is certainly encouraging, despite the fact that our study is restricted to just one QBO cycle, and it should provide motivation for further studies of the westerly phase of the SAO using MLS-observed waves [the reader is referred to Canziani et al. (1994) for an analysis of Kelvin waves in MLS data ]. As for the easterly phase, one notes that the onset of SAO easterlies tends to occur simultaneously over a deep layer, which seems to be inconsistent with forcing by vertically propagating waves. Instead, meridional advection of easterly momentum and/or absorption of horizontally propagating stationary Rossby waves near the zero-wind line are commonly invoked to explain the easterly phase. How- ever, in several modeling studies the advection mechanism, while important right at the equator, proved to be incapable of producing easterlies as far as 20 degrees from the equator (Meyer 1970; Holton and Wehrbein 1980; Takahashi 1984), thus implying a greater role for the critical line absorption (Hopkins 1975). Note that our summer easterlies do in fact reach $20^{\circ}$ in the winter hemisphere (see Fig. 6).

\section{b. Implications for stratospheric transport}

The implications of the tropical SAO for the distribution of chemical tracers have been studied by Solomon et al. (1986), Gray and Pyle (1986), Gille et al. (1987), and Choi and Holton (1991). In particular, those investigators noted the role played by the region of downwelling in producing the "double-peaked" structure in the distributions of water vapor, nitrous oxide, and methane. The distribution of water vapor measured by MLS is shown in Fig. 13. It shows a "doublepeaked" structure in low latitudes in the March-May period of 1992 and 1993 and in October 1992. The fact that the double peak is more pronounced around the vernal equinox, with $\mathrm{H}_{2} \mathrm{O}$ mixing ratios exceeding 7 ppmv at $1 \mathrm{hPa}$ at the equator in the spring of 1993, and that the double peak is missing entirely in the fall of 1991, seems to be consistent with the downward vertical velocities at the equatorial stratopause being larger during the northern winter phase of the SAO. In the present study, downward velocities at the tropical stratopause exceed $1 \mathrm{~mm} \mathrm{~s}^{-1}$ in March 1992 and in March 1993 they even exceed $2 \mathrm{~mm} \mathrm{~s}^{-1}$. We note that downward velocities in excess of $1 \mathrm{~mm} \mathrm{~s}^{-1}$ were required by Choi and Holton (1991) in order to produce the equinoctial double peak in the distribution of nitrous oxide. The extreme negative values of $\bar{w}^{*}$ in the Tropics are in excess of $3.5 \mathrm{~mm} \mathrm{~s}^{-1}$ and are thus even larger than the values obtained by Choi and Holton in their scheme modified to enhance the equatorial vertical velocities (see their Fig. 12). In 1993, our vertical velocities are slightly negative in the equatorial upper stratosphere as late as May, whereas Choi and Holton were unable to sustain large negative $\bar{w}^{*}$ in their study, mainly because the SAO signal in the climatological fields of temperature they used was too small. One notable difference between the double peak in the water vapor distribution observed by LIMS and MLS is the vertical extent of this feature, which extends down to almost $10 \mathrm{hPa}$ in the LIMS field, but only to about 2 $\mathrm{hPa}$ in the MLS distribution. The deep vertical extent of the LIMS double peak proved difficult to simulate with the residual circulation diagnosed from LIMS (Solomon et al. 1986; Gille et al. 1987), since in the latter the equatorial downwelling extended down only to about $1-2 \mathrm{hPa}$. However, if the smaller vertical extent of the MLS water vapor double peak is real, then it should be easier to simulate with our residual circulation, whose downward branch at the equator also ex- 


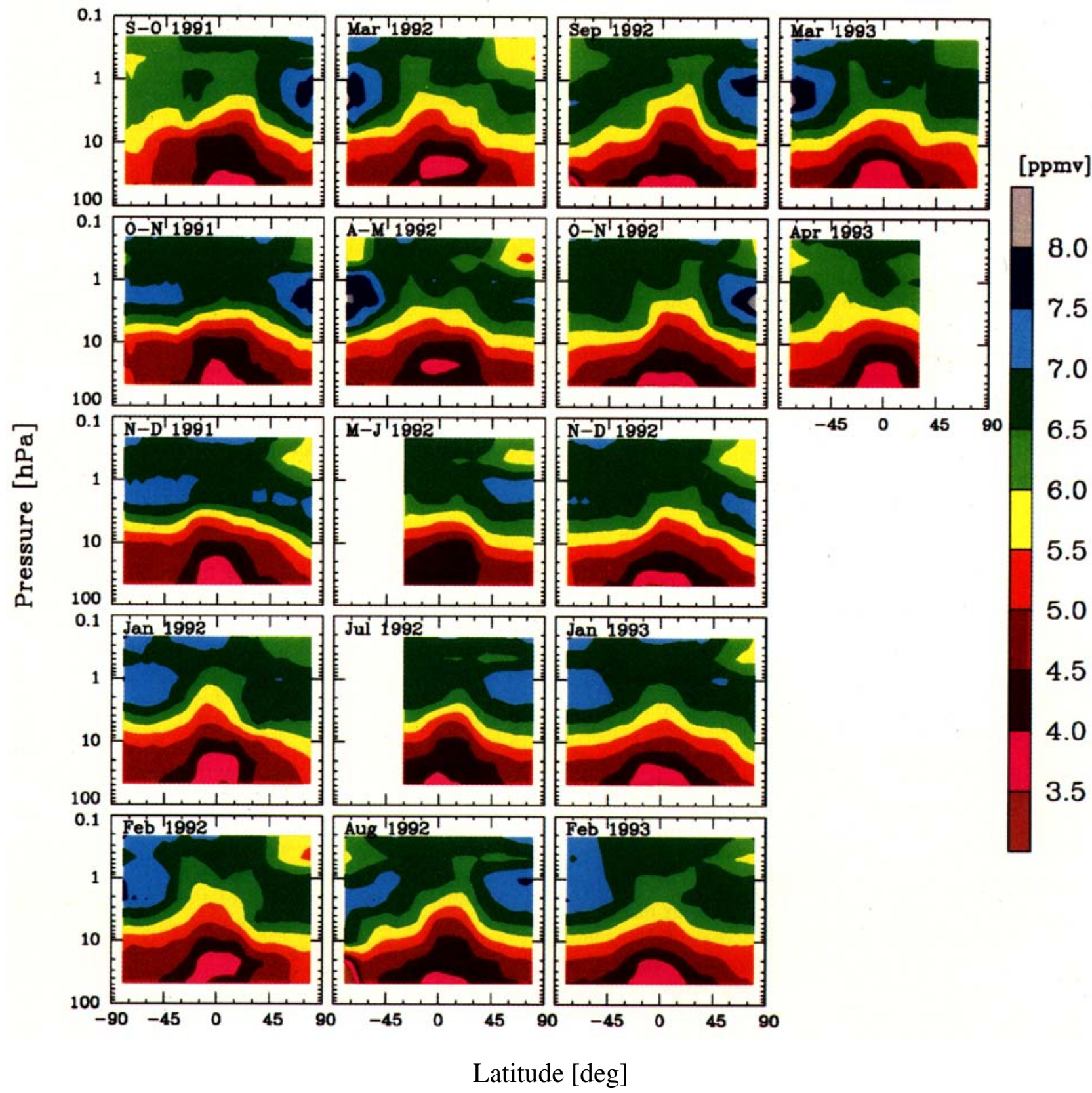

FIG. 13. Latitude-height sections of the water vapor mixing ratio (in ppmv). MLS water vapor data are not available for the period 1 June-16 July 1992 and after 25 April 1993.

tends down to about $2 \mathrm{hPa}$. The full linkage between the SAO and the "double-peaked" structure can be established only by means of a chemical tracer model, and we intend to run such a model, with our residual circulation used as input, in the near future. We conclude by noting a link between SAO and ozone: models based on climatological temperature fields or fields derived from operational analyses, despite their overall success in reproducing the distributions of long-lived tracers, have not been able (due to the greatly reduced or absent SAO signal in those fields) to reproduce the observed methane distribution in the upper stratosphere (e.g., Yang et al. 1991) and this may contribute, via its effect on the resulting $\mathrm{ClO}$ distribution, to the longstanding model "ozone-deficit" problem (Eluszkiewicz and Allen 1993).

\section{Summary}

With the advent of the Upper Atmosphere Research Satellite, it has become possible to study the residual 
circulation in the middle atmosphere with good vertical resolution over several seasonal cycles. In this paper, this circulation has been diagnosed from measurements acquired by the Microwave Limb Sounder onboard $U A R S$. The vertical component of this circulation undergoes a semiannual oscillation (SAO) in the tropical upper stratosphere and lower mesosphere, which is related to the SAO in temperature and ozone. Our results also indicate a possible quasi-biennial oscillation in the tropical vertical velocities, which were significantly smaller in 1993-1994 than in 1992-1993. Significant intraseasonal and interannual variability in the diagnosed vertical velocities is also observed at high latitudes during northern winter. This variability is consistent with the wave forcing computed as the residual in the momentum equation. Since it contains a robust SAO component, the computed circulation should lead to improvements in the two-dimensional modeling of constituents exhibiting a "double-peaked" distribution in low and middle latitudes, in particular water vapor, nitrous oxide, and methane. In the lower stratosphere, where our circulation implies a rather small downward mass flux in high latitudes in summer, a consistency check might be provided by model simulations of total ozone (Y. Yung 1995, personal communication).

Acknowledgments. M. F. Gerstell is thanked for her assiduity in assembling the cloud and albedo climatology, collaboration in debugging the radiative transfer model, and testing its sensitivities to tropospheric and surface fields. K. Rosenlof, K. K. Tung, and an anonymous reviewer provided critical reviews; comparisons using the Olaguer et al. (1992) radiative transfer code helped us to correct a coding error in our radiative model. G. Rottman and C. Pankratz of the SOLSTICE team are thanked for supplying the solar flux data, specially processed for our averaging periods. I. Fung and S. Massie provided us with information on the NASA GISS database and on the $\mathrm{CO}_{2}$ concentrations, respectively. M. Delitsky assisted in the creation of the Fourier coefficient files from which temperature and constituent fields were constructed. M. Santee provided the streamfunction code and G. Manney the 100-hPa geopotential heights and the UKMO meteorological fields. Comments by A. Plumb are appreciated, in particular, his suggestion about the lower boundary condition for the streamfunction equation. H. Yang and R. Rood also provided helpful comments. R. Atkinson helped with the graphics at MIT. T. Luu is thanked for data management and help with the graphics at JPL. Y. Yung, E. Chang, and E. De Jong are thanked for the use of their computer facilities. This research was carried out as part of UARS Investigations at JPL/Caltech under contract with NASA and at Edinburgh and Heriot-Watt Universities sponsored by SERC. Oxford authors acknowledge funding by the Natural Environment Research Council.

\section{APPENDIX}

\section{Treatment of Clouds and Surface Albedo}

The fractional cloud coverage by high, middle, and low clouds has been obtained from the monthly averages distributed by the International Satellite Cloud Climatology Project (ISCCP) (Rossow and Schiffer 1991 ). Since data for 1992-94 are not available yet, we used interannually averaged data for 1984-86. Cloud-top heights for the three levels were also taken from ISCCP, but we did not use ISCCP-supplied optical thicknesses or cloud types, instead taking all high clouds to be cirrus, all middle-level clouds to be altostratus, and all low clouds to be stratocumulus. The assumed visible optical depths are 10,5 , and 1.5 for the low, middle, and high clouds, respectively. It should be noted that the Mt. Pinatubo aerosol is thought to have affected the occurence of high-level cloud (Sassen et al. 1995); this effect is not accounted for in the present paper. The wavelength-dependent extinction, absorption, and scattering cross sections, and the scattering phase functions for liquid water clouds have been derived by means of a model that combines a Miescattering algorithm (Wiscombe 1980 and 1992, personal communication) with the methods used to integrate over particle size distributions described by Hansen and Travis (1974). Cloud particle size distributions for altostratus (middle) and stratus (low) clouds are taken from Hansen (1971). Refractive indices for liquid water are taken from Hale and Querry (1973). For cirrus clouds, we use the wavelength-dependent optical properties for columnar ice columns (Freeman and Liou 1979).

At the lower boundary, we assume a Lambertian surface, with the visible albedos taken from ISCCP data. In the near-infrared, the ratio of the surface near-IR albedo to visible albedo depends on surface type and is approximated by the expressions of Briegleb (1992). Latitudinal distributions of surface vegetation have been obtained from the NASA Goddard Institute for Space Studies database (see Matthews 1983) and the ISCCP ice-and-snow fraction is incorporated into the calculation in order to arrive at a probable near-IR albedo for each month and zonal band. Thermal infrared surface albedos are taken from Warren (1982) for snow, assumed to be zero for dry land, and calculated explicitly for ocean, including the effect of increased sea surface roughness as one goes from the Tropics to high latitudes. An in-depth investigation of the impact of boundary conditions on the heating calculations has been carried out by Gerstell (1995).

\section{REFERENCES}

Andrews, D. G., J. R. Holton, and C. B. Leovy, 1987: Middle Atmosphere Dynamics. Academic Press, 489 pp.

Bell, J. F., III, and D. Crisp, 1993: Groundbased imaging spectroscopy of Mars in the near-infrared: Preliminary results. Icarus, 104, 2-19. 
Briegleb, B. P., 1992: Delta-Eddington approximation to solar radiation in the NCAR Community Climate Model. J. Geophys. Res., 97, 7603-7612.

Callis, L. B., R. E. Bougher, and J. D. Lambeth, 1987: The stratosphere: Climatologies of the radiative heating and cooling rates and the diabatically diagnosed net circulation fields. J. Geophys. Res., 92, 5585-5607.

Canziani, P. O., J. R. Holton, E. Fishbein, L. Froidevaux, and I. Waters, 1994: Equatorial Kelvin waves: A UARS MLS view. J. Atmos. Sci., 51, 3053-3076.

Choi, W. K., and J. R. Holton, 1991: Transport of $\mathrm{N}_{2} \mathrm{O}$ in the stratosphere related to the equatorial semiannual oscillation. J. Geophys. Res., 96, 22 543-22 557.

Crisp, D., 1986: Radiative forcing of the Venus mesosphere. Part I: Solar fluxes and heating rates. Icarus, 67, 484-514.

- 1989: Radiative forcing of the Venus atmosphere. Part II: Thermal fluxes, cooling rates, and radiative equilibrium temperatures. Icarus, 77, 391-413.

- 1990: Infrared radiative transfer in the dust-free martian atmosphere. J. Geophys. Res., 95, 14 577-14 588.

- S. B. Fels, and M. D. Schwarzkopf, 1986: Approximate methods for finding $\mathrm{CO}_{2} 15 \mu \mathrm{m}$ band transmission in planetary atmospheres. J. Geophys. Res., 91, 11 851-11 866.

DeMore, W. B., D. M. Golden, R. F. Hampson, M. J. Kurylo, C. J. Howard, A. R. Ravishankara, C. E. Kolb, and M. J. Molina 1992: Chemical kinetics and photochemical data for use in stratospheric sodeling. JPL Publ. JPL 92-20, 185 pp.

Dunkerton, T., 1979: On the role of the Kelvin wave in the westerly phase of the semiannual zonal wind oscillation. J. Atmos. Sci., $36,32-41$.

- 1989: Nonlinear Hadley circulation driven by asymmetric differential heating. J. Atmos. Sci., 46, 956-974.

Elson, L. S., and L. Froidevaux, 1993: Use of Fourier transforms for asynoptic mapping: Applications to the Upper Atmosphere Research Satellite Microwave Limb Sounder. J. Geophys. Res., 98, 23 039-23 049.

Eluszkiewicz, J., and M. Allen, 1993: A global analysis of the ozone deficit in the upper stratosphere and lower mesosphere. J. Geophys. Res., 98, 1069-1082.

—, R. A. Plumb, and N. Nakamura, 1995: Dynamics of wintertime stratospheric transport in the Geophysical Fluid Dynamics Laboratory "SKYHI" general circulation model. J. Geophys. Res. $100,20883-20900$.

Fishbein, E. F., and Coauthors, 1994: Validation of UARS MLS temperature and pressure measurements. J. Geophys. Res., in press.

Freeman, K. P., and K.-N. Liou, 1979: Climatic effects of cirrus clouds. Advances in Geophysics, Vol. 21, Academic Press, 231287.

Froidevaux, L., J. W. Waters, W. G. Read, L. S. Elson, D. A. Flower, and R. F. Jarnot, 1994a: Global ozone observations from UARS MLS: An overview of zonal mean results. J. Atmos. Sci, 51, 2846-2866.

surements. J. Geophys. Res., in press.

Garcia, R. R., and S. Solomon, 1983: A numerical model of the zonally averaged dynamical and chemical structure of the middle atmosphere. J. Geophys. Res., 88, 1379-1400.

Geller, M. A., E. R. Nash, M.-F. Wu, and J. A. Rosenfield, 1992: Residual circulations calculated from satellite data: Their relations to observed temperature and ozone distributions. J. Atmos. Sci., 49, 1127-1137.

Gerstell, M. F., 1995: Two radiative transfer models with terrestrial applications. Ph.D. thesis, California Institute of Technology, $140 \mathrm{pp}$.

- J. Crisp, and D. Crisp, 1995: Radiative forcing of the stratosphere by $\mathrm{SO}_{2}$ gas, silicate ash, and $\mathrm{H}_{2} \mathrm{SO}_{4}$ aerosols shortly after the 1982 eruptions of El Chichón. J. Climate, 8, 1060-1070.

Gille, J. C., L. V. Lyjak, and A. K. Smith, 1987: The global residual mean circulation in the middle atmosphere for the northern winter period. J. Atmos. Sci., 44, 1437-1452.
Goody, R. M., and Y. L. Yung, 1989: Atmospheric Radiation: Theoretical Basis. Oxford University Press, $519 \mathrm{pp}$.

Grainger, R. G., A. Lambert, C. D. Rodgers, and F. W. Taylor, 1995a: Properties of the Mt. Pinatubo Aerosol cloud determined from ISAMS measurements at $12.1 \mu \mathrm{m}$. Proc. NATO Advanced Research Workshop, The Effects of the Mt. Pinatubo Eruption on the Atmosphere and Climate, Springer-Verlag, in press.

_ _ _ _ _ _ _ _ a , and T. Deshler, 1995b: Stratospheric aerosol effective radius, surface area and volume estimated from infrared measurements. J. Geophys. Res., 100, $16507-16518$.

Gray, L. J., and J. A. Pyle, 1986: The semi-annual oscillation and equatorial tracer distributions. Quart. J. Roy. Meteor. Soc., 112 , 387-407.

Hale, G. M., and M. R. Querry, 1973: Optical constants of water in the $200-\mathrm{nm}$ to $200-\mu \mathrm{m}$ wavelength region. Appl. Opt., 12, 555563.

Hansen, J. E., 1971: Multiple scattering of polarized light in planetary atmospheres. Part II: Sunlight reflected by terrestrial water clouds. J. Atmos. Sci., 28, 1400-1426.

_- and L. D. Travis, 1974: Light scattering in planetary atmospheres. Space Sci. Res., 16, 527-610.

Hartmann, D. L., 1976: The dynamical climatology of the stratosphere in the Southern Hemisphere during late winter 1973. $J$. Atmos. Sci., 33, 1789-1802.

Haynes, P. H., C. J. Marks, M. E. McIntyre, T. G. Sheperd, and K. P. Shine, 1991: On the "downward control" of extratopical diabatic circulations by eddy-induced mean zonal forces. $J$. Atmos. Sci., 48, 651-678.

Hitchman, M. H., 1985: An observational study of wave-mean flow interaction in the equatorial middle atmosphere. Ph.D. thesis, University of Washington, $360 \mathrm{pp}$.

- and C. B. Leovy, 1986: Evolution of the zonal mean state in the equatorial middle atmosphere during October 1978-May 1979. J. Atmos. Sci., 43, 3159-3176.

Holton, J, R., 1990: On the global exchange of mass between the stratosphere and troposphere. J. Atmos. Sci., 47, 392-395.

- and W. M. Wehrbein, 1980: A numerical model of the zonal mean circulation of the middle atmosphere. Pure Appl. Geophys., 118, 284-306.

Hopkins, R. H., 1975: Evidence of polar-tropical coupling in upper stratospheric zonal wind anomalies. J. Atmos. Sci., 32, 712719.

Humliček, J., 1982: Optimized computation of the Voigt and complex probability distributions. J. Quant. Spectrosc. Radiat. Transfer, 27, 437-444.

Iwasaki, T., 1992: General circulation diagnosis in the pressure-isentrope hybrid vertical coordinate. J. Meteor. Soc. Japan, 70, 673-687.

Keeling, C. D., R. B. Bacastow, A. F. Carter, S. C. Piper, T. P. Whorf, M. Heiman, W. G. Mook, and H. Roeloffzen, 1989: A threedimensional model of atmospheric $\mathrm{CO}_{2}$ transport based on observed winds. Part 1: Analysis of observational data. Aspects of Climate Variability in the Pacific and Western Americas, Geophys. Monogr. No. 55, Amer. Geophys. Union, 165-236.

Kinne, S., O. B. Toon, and M. J. Prather, 1992: Buffering of the stratospheric circulation by changing amounts of tropical ozone: A Pinatubo case study. Geophys. Res. Lett., 19, 1927-1930.

Kinnison, D. E., K. E. Grant, P. S. Connell, D. A. Rotman, and D. J. Wuebbles, 1994: The chemical and radiative effects of the Mount Pinatubo eruption. J. Geophys. Res., 99, 25 705-25 731.

Lahoz, W. A., and Coauthors, 1994: Validation of UARS MLS 183 $\mathrm{GHz}_{2} \mathrm{O}$ measurements. J. Geophys. Res., in press.

Lait, L. R., and J. L. Stanford, 1988: Applications of asynoptic space-time Fourier transform methods to scanning satellite measurements. J. Atmos. Sci., 45, 3784-3809.

Lambert, A., R. G. Grainger, J. J. Remedios, W. J. Reburn, C. D. Rodgers, F. W. Taylor, A. E. Roche, J. B. Kumer, S. T. Massie, and T. Deshler, 1995: Validation of aerosol measurements from the Improved Stratospheric and Mesospheric Sounder. J. Geophys. Res., in press. 
Leovy, C. B., 1964: Simple model of thermally driven mesospheric circulation. J. Atmos. Sci., 21, 327-341.

Liou, K.-N., 1980: An Introduction to Atmospheric Radiation. Academic Press, 392 pp.

Luther, F. M., and Y. Fouquart, 1984: The intercomparison of radiation codes in climate models (ICRCCM). WMO Rep. WCP$93,37 \mathrm{pp}$.

Matthews, E., 1983: Global vegetation and land use: New high-resolution data bases for climate studies. J. Climate Appl. Meteor., 22, 474-487.

Meyer, W. D., 1970: A diagnostic numerical study of the semi-annual variation of the zonal wind in the tropical stratosphere and mesosphere. J. Atmos. Sci., 27, 820-830.

Mote, P. W., K. H. Rosenlof, J. R. Holton, R. S. Harwood, and J. W. Waters, 1995: Seasonal variations of water vapor in the tropical lower stratosphere. Geophys. Res. Lett., 22, 1093-1096.

Murgatroyd, R. J., and R. M. Goody, 1958: Sources and sinks of radiative energy from 30 to $90 \mathrm{~km}$. Quart. J. Roy. Meteor. Soc., 84, 225-234.

stratosphere and mesosphere. Quart. J. Roy. Meteor. Soc., 87, 125-135.

Nielsen, J. E., R. B. Rood, A. R. Douglass, M. C. Cerniglia, D. J. Allen, and J. E. Rosenfield, 1994: Tracer evolution in winds generated by a global spectral mechanistic model. J. Geophys. Res., 99, 5399-5420.

Olaguer, E. P., H. Yang, and K. K. Tung, 1992: A reexamination of the radiative balance of the stratosphere. J. Atmos. Sci., 49, $1242-1263$.

Pawson, S., and R. S. Harwood, 1989: Monthly-mean diabatic circulations in the stratosphere. Quart. J. Roy. Meteor. Soc., 115, 807-840.

Ray, E., J. R. Holton, E. F. Fishbein, L. Froidevaux, and J. W. Waters, 1994: The tropical semiannual oscillation (SAO) in temperature and ozone as observed by the Microwave Limb Sounder (MLS). J. Atmos. Sci., 51, 3045-3052.

Reber, C. A., C. E. Trevathan, R. J. McNeal, and M. R. Luther, 1993: The Upper Atmosphere Research Satellite (UARS) mission. $J$. Geophys. Res., 98, 10 643-10 647.

Reed, R. J., 1966: Zonal wind behavior in the equatorial stratosphere and lower mesosphere. J. Geophys. Res., 71, 4223-4233.

_- and C. L. Vlcek, 1969: The annual temperature variation in the lower stratosphere. J. Atmos. Sci., 26, 163-167.

Roberts, R. E., J. E. A. Selby, and L. M. Biberman, 1976: Infrared continuum absorption by atmospheric water vapor in the 8-12 $\mu \mathrm{m}$ window. Appl. Opt., 15, 2085-2090.

Rosenfield, J. E., M. R. Schoeberl, and M. A. Geller, 1987: A computation of the stratospheric diabatic circulation using an accurate radiative transfer model. J. Atmos. Sci., 44, 859-876.

Rosenlof, K. H., and J. R. Holton, 1993: Estimates of the stratospheric residual circulation using the downward control principle. J. Geophys. Res., 98, $10465-10479$.

Rossow, W. B., and R. A. Schiffer, 1991: ISCCP cloud data products. Bull. Amer. Meteor. Soc., 72, 2-20.

Rothman, L. S., 1992: The HITRAN molecular database: Editions of 1991 and 1992. J. Quant. Spectrosc. Radiat. Transfer, 48, 469509.
Rottman, G. J., T. N. Woods, and T. P. Sparn, 1993: Solar Stellar Irradiance Comparison Experiment I. Part 1: Instrument design and operation. J. Geophys. Res., 98, $10667-10677$.

Russell, J. M., III, J. C. Gille, E. M. Remsberg, L. L. Gordley, P. L. Bailey, H. Fisher, A. Girard, S. R. Drayson, W. F. J. Evans, and J. E. Harries, 1984: Validation of water vapor results measured by the Limb Infrared Monitor of the Stratosphere experiment on Nimbus 7. J. Geophys. Res., 89, 5115-5124.

Salby, M. L., 1982: Sampling theory for asynoptic satellite observations. Part I: Space-time spectra, resolution, and aliasing. $J$. Atmos. Sci., 39, 2577-2600.

Santee, M. L., and D. Crisp, 1993: Thermal structure and dust loading of the martian atmosphere during late southern summer: Mariner 9 revisited. J. Geophys. Res., 98, 3261-3279.

$\ldots$, and — 1995: Diagnostic calculations of the circulation in the martian atmosphere. J. Geophys. Res., 100, 5465-5485.

Sassen, K., D. O'C. Starr, G. G. Mace, M. R. Poellot, S. H. Melfi, W. L. Eberhard, J. D. Spinhirne, E. W. Eloranta, D. E. Hagen, and J. Hallett, 1995: The 5-6 December 1991 FIRE IFO II jet stream cirrus case study: Possible influences of volcanic aerosols. J. Atmos. Sci., 52, 97-123.

Schoeberl, M. R., L. R. Lait, P. A. Newman, and J. E. Rosenfield, 1992: The structure of the polar vortex. J. Geophys. Res., 97, 7859-7882.

Shine, K., 1989: Sources and sinks of zonal momentum in the middle atmosphere diagnosed using the diabatic circulation. Quart. $J$. Roy. Meteor. Soc., 115, 265-292.

Solomon, S., J. T. Kiehl, R. R. Garcia, and W. Grose, 1986: Tracer transport by the diabatic circulation deduced from satellite observations. J. Atmos. Sci., 43, 1603-1617.

Swinbank, R., and A. O'Neill, 1994: A stratosphere-troposphere data assimilation system. Mon. Wea. Rev., 122, 686-702.

Takahashi, M., 1984: A 2-dimensional numerical model of the semiannual zonal wind oscillation. Dynamics of the Middle Atmosphere, J. R. Holton and T. Matsuno, Eds., Terra Scientific Publishing Company, 253-269.

Thekaekara, M. P., R. Kruger, and C. H. Duncan, 1969: Solar irradiance measurements from a research aircraft. Appl. Opt., 8, 1713-1732.

Warren, S. G., 1982: Optical properties of snow. Rev. Geophys. Space Phys., 20, 67-89.

Waters, J. W., L. Froidevaux, W. G. Read, G. L. Manney, L. S. Elson, D. A. Flower, R. F. Jarnot, and R. S. Harwood, 1993: Stratospheric $\mathrm{ClO}$ and ozone from the Microwave Limb Sounder on the Upper Atmosphere Research Satellite. Nature, 362, 597-602.

Wiscombe, W. J., 1980: Improved Mie scattering algorithms. Appl. Opt., 19, 1505-1509.

World Meteorological Organization, 1986: Atmospheric Ozone 1985. WMO Global Ozone Research and Monitoring Project Rep. No. 16, Vol. 1, 392 pp.

Yang, H., E. Olaguer, and K. K. Tung, 1991: Simulation of the present-day atmospheric ozone, odd nitrogen, chlorine, and other species using a coupled 2-D model in isentropic coordinates. $J$. Atmos. Sci., 48, 442-471.

Yulaeva, E., J. R. Holton, and J. M. Wallace, 1994: On the cause of the annual cycle in tropical lower-stratospheric temperatures. $J$. Atmos. Sci., 51, 169-174. 